\title{
mTOR inhibition rescues osteopenia in mice with systemic sclerosis
}

\author{
Chider Chen, ${ }^{1,2} *$ Kentaro Akiyama, ${ }^{1,3 *}$ Dandan Wang, ${ }^{4}$ Xingtian Xu, ${ }^{1,5}$ \\ Bei Li, ${ }^{1,6}$ Alireza Moshaverinia, ${ }^{1}$ Frank Brombacher, ${ }^{7}$ Lingyun Sun, ${ }^{4}$ \\ and Songtao $\mathrm{Shi}^{1}$
}

\section{CORRESPONDENCE}

Songtao Shi:

songtaos@dental.upenn.edu OR

Lingyun Sun:

lingyunsun2012@163.com

Abbreviations used: ALP, alkaline phosphatase; ANC, allnuclear cell; BMD, bone mineral density; BMMSC, BM mesenchymal stem cell; BV/TV, bone volume versus total volume; CFU-F, colony forming unit-fibroblast; ChIP, chromatin immunoprecipitation; CTX, cross-linked telopeptide; FBN1, fibrillin-1; HA/TCP, hydroxyapatite tricalcium phosphate; IHC, immunohistochemical; LPL, lipoprotein lipase; OCN, osteocalcin; OPG, osteoprotegerin; PI3K, phosphoinositide 3-kinase; PPAR $\gamma 2$, peroxisome proliferatoractivated receptor $\gamma 2$; sRANKL, soluble receptor activator of nuclear factor $\kappa \mathrm{B}$ ligand; SSc, systemic sclerosis; STAT6, signal transducer and activator of transcription-6; TKO, triple conditional KO; TRAP, tartrateresistant acid phosphate.

\author{
${ }^{1}$ Center for Craniofacial Molecular Biology, Ostrow School of Dentistry, University of Southern California, Los Angeles, CA 90033 \\ 2Department of Anatomy and Cell Biology, School of Dental Medicine, University of Pennsylvania, Philadelphia, PA 19104 \\ ${ }^{3}$ Department of Oral Rehabilitation and Regenerative Medicine, Okayama University Graduate School of Medicine, Dentistry, \\ and Pharmaceutical Science, Kita-ku, Okayama 700-8525, Japan \\ ${ }^{4}$ Department of Rheumatology and Immunology, the Affiliated Drum Tower Hospital of Nanjing University Medical School, \\ Nanjing 210008, China \\ ${ }^{5}$ Key Laboratory of Translational Research, Tong Ji University School of Stomatology, Shanghai 200072, China \\ ${ }^{6}$ School of Stomatology, Fourth Military Medical University, Xi'an 710032, Shaanxi, China \\ 'Division of Immunology, Cape Town Component and Institute of Infectious Diseases and Molecular Medicine (IIDMM), \\ International Center for Genetic Engineering and Biotechnology (ICGEB) University of Cape Town, Cape Town 7925, South Africa
}

Fibrillin-1 (FBN1) deficiency-induced systemic sclerosis is attributed to elevation of interleukin-4 (IL4) and TGF- $\beta$, but the mechanism underlying FBN1 deficiency-associated osteopenia is not fully understood. We show that bone marrow mesenchymal stem cells (BMMSCs) from FBN1-deficient $\left(\mathrm{Fbn}^{+/-}\right.$) mice exhibit decreased osteogenic differentiation and increased adipogenic differentiation. Mechanistically, this lineage alteration is regulated by IL4/IL4R $\alpha$-mediated activation of mTOR signaling to down-regulate RUNX2 and up-regulate PPAR 22, respectively, via P70 ribosomal S6 protein kinase (P70S6K). Additionally, we reveal that activation of TGF- $\beta / S M A D 3 / S P 1$ signaling results in enhancement of SP1 binding to the IL4R $\alpha$ promoter to synergistically activate mTOR pathway in

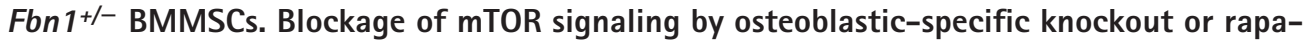
mycin treatment rescues osteopenia phenotype in Fbn $1^{+-}$mice by improving osteogenic differentiation of BMMSCs. Collectively, this study identifies a previously unrecognized role of the FBN1/TGF- $\beta /$ IL4R $\alpha / m$ TOR cascade in BMMSC lineage selection and provides experimental evidence that rapamycin treatment may provide an anabolic therapy for osteopenia in $\mathrm{Fbn} 1^{+/-}$mice.

Fibrillin-1 (FBN1), a major structural component of microfibrils in extracellular matrix plays an important role in organ development and tissue homeostasis (Sakai et al., 1986; Zhang et al., 1995). Recent studies show that LTBP-1 (latent transforming growth factor- $\beta$ binding protein-1) interacts with FBN1 through its pro-domains (Charbonneau et al., 2004; Ramirez and Sakai, 2010). Thus, Fbn1 deficiency increases the level of activated TGF- $\beta$ in the intercellular microenvironment. Clinically, Fbn 1 gene mutation is linked to several human diseases, including systemic sclerosis (SSc)/scleroderma, Marfan's syndrome, ectopic lentis, and the dominant form of Weill-Marchesani syndrome (Lee et al., 1991; Charbonneau et al., 2004). These diseases are

\footnotetext{
*C. Chen and K. Akiyama contributed equally to this paper.
}

usually characterized by connective tissue fibrosis and skeletal disorders, but it is unclear whether Fbn1 deficiency contributes to bone disorders in these diseases.

As an established SSc mouse model, Fbn 1 partial intragenic duplication mutant tight-skin mice (B6.Cg- Fbn 1 ${ }^{\text {Tsk }} / \mathrm{J} ; \mathrm{Fbn1}^{+/-}$) show significantly reduced femoral bone mineral density (BMD) and altered trabecular microarchitecture (Barisic-Dujmovic et al., 2007). Loss of function of $F b n 1$ induced a bone disorder involving elongated bone length and reduced bone density, similar to Marfan syndrome (Dietz et al., 1991, 1994; Lee et al., 1991; Quarto et al., 2012),

2015 Chen et at. This article is distributed under the terms of an AttributionNoncommercial-Share Alike-No Mirror Sites license for the first six months after the publication date (see http://www.rupress.org/terms). After six months it is
then available under a Creative Commons License (Attribution-Noncommercial-Share Alike 3.0 Unported license, as described at http://creativecommons.org/licenses/ by-nc-sa/3.0/). 
A

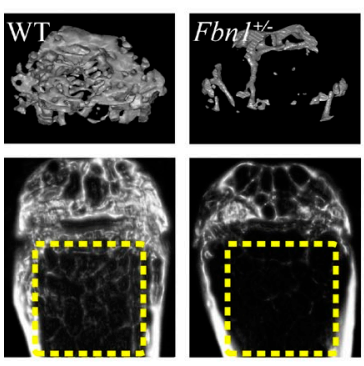

B

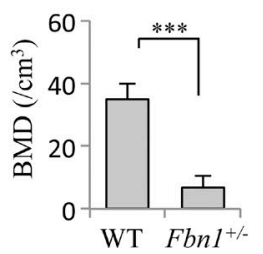

C

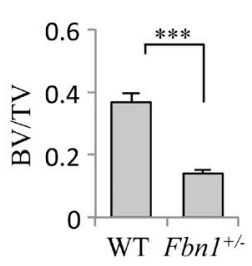

$\mathrm{D}$
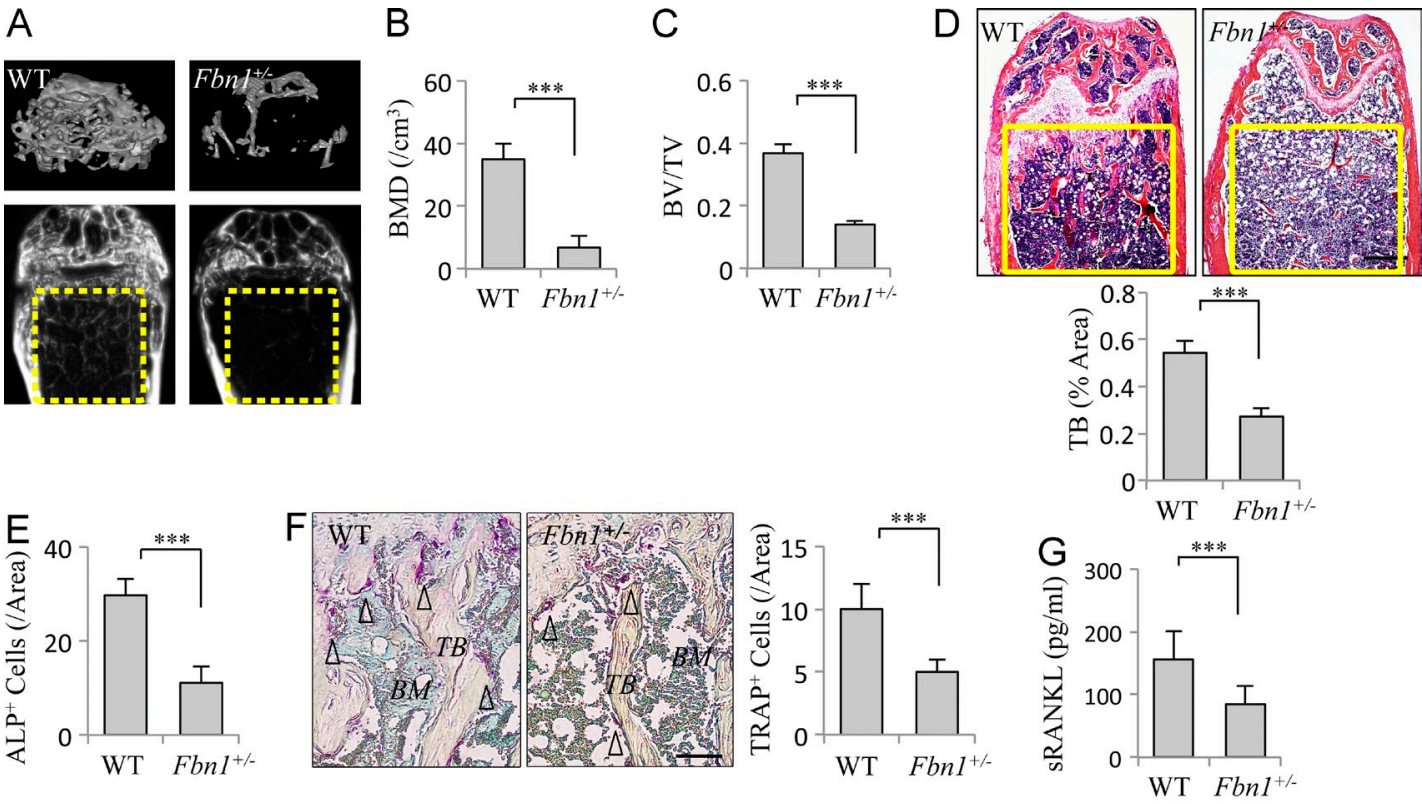
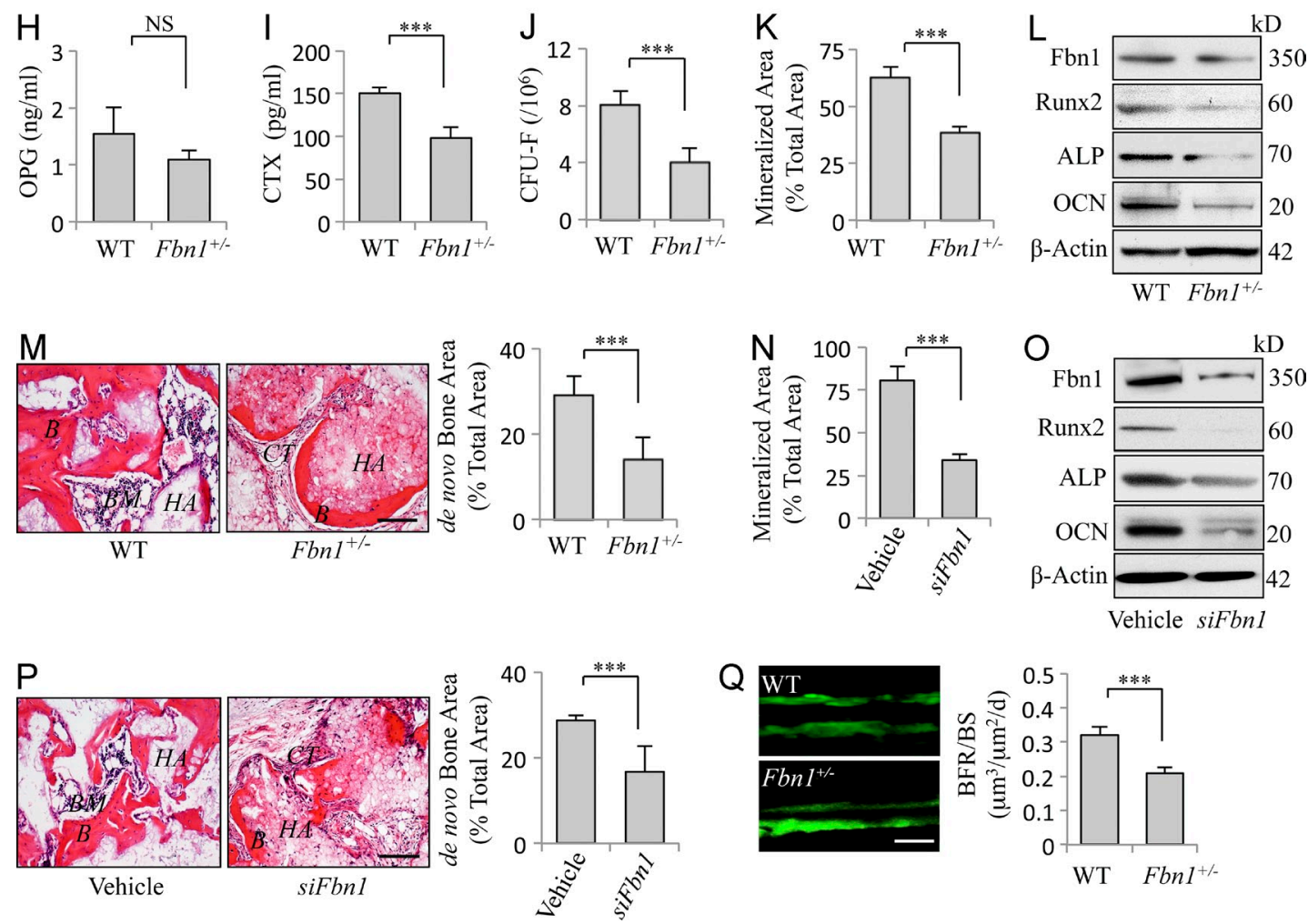

Figure 1. Fbn1-deficient $($ Fbn 1+/-) mice exhibit osteopenia phenotype. (A-C) MicroCT (A), BMD (B), and BV/TV (C) analysis of trabecular bone (TB) area in WT and Fon $1^{+-}$mouse distal femurs. (D) H\&E staining of TB volume (yellow square) in distal femurs of Fon $1^{+/-}$mice $(n=15)$ and WT littermates $(n=10)$. Bar, $1 \mathrm{~mm}$. (E) IHC staining of ALP+ osteoblasts in Fbn $1^{+/-}$mice and WT littermates. (F) TRAP staining of osteoclasts in distal femur trabecular bone (TB) and BM in WT and Fbn $1^{++-}$mice. Arrowheads, TRAP+ osteoclasts (purple cells). Bar, $25 \mu \mathrm{m}$. (G-I) ELISA analysis of serum sRANKL (G), OPG (H), and CTX (I) in Fbn $1^{+/-}$mice and WT littermates. (J) Toluidine blue staining showed the number of CFU-F from WT and Fon $1^{+/-}$BMMSCs. (K and N) Alizarin red staining of Fbn 1+/- (K) and Fbn 1 siRNA knockdown (N) BMMSCs showed the capacity to form mineralized nodules when cultured under osteoinductive conditions. (L and 0 ) Western blot analysis of Fon $1^{+/-}(L)$ and Fon 1 siRNA knockdown (0) BMMSCs showed expressed levels of FBN1 and the osteogenic genes RUNX2, ALP, and OCN. $\beta$-Actin was used as a protein loading control. (M and P) Subcutaneous implantation of BMMSCs in immunocompromised mice showed that bone (B), BM, and connective tissue (CT) were generated around HA/TCP (HA) at 8 wk after implantation. Bars, $50 \mu \mathrm{m}$. A semiquantitative analysis showed the amount of bone formation in BMMSC implants. (0) Calcein double labeling of the metaphyseal trabecular bone in the distal femora showed the bone turnover rate in WT and Fon $1^{+/-}$mice. Bar, $25 \mu \mathrm{m}$. All experimental data verified in at least three independent experiments. Error bars represent the SD from the mean values. ${ }^{* * *}, P<0.005 ;$ NS, not significant. 
suggesting that dysregulation of TGF- $\beta$ signaling by Fbn 1 mutation is the major factor underlying this bone deficiency (Judge et al., 2004; Dietz et al., 2005; Lemaire et al., 2006). Fbn $1^{+/-}$mice represent an autoimmune connective tissue disorder characterized by type 2 helper $\mathrm{T}$ cell $\left(\mathrm{T}_{\mathrm{H}} 2\right.$ cell $)$ infiltration and vascular damage (Gabrielli et al., 2009). IL4, a key $\mathrm{T}_{\mathrm{H}} 2$ cytokine plays a critical role in the regulation of fibrotic tissue deposition through the signal transducer and activator of transcription-6 (STAT6) pathway (Wynn, 2004). Although the mechanism that results in an elevated level of IL4 in $\mathrm{Fbn} 1^{+/-}$mice is unknown, down-regulation of the Il4 gene in $\mathrm{Fbn} 1^{+/-}$mice can rescue the pathogenesis in fibrotic diseases, suggesting that IL4 signaling is associated with fibrotic phenotype in SSc (Kodera et al., 2002). However, it is unknown whether IL4 signaling contributes to the osteoporotic phenotype in SSc mice.

BM mesenchymal stem cells (BMMSCs) constitute a population of self-renewal and multipotent cells that can differentiate into osteoblasts, adipocytes, fibroblasts, chondrocytes and nonmesenchymal cell types (Friedenstein et al., 1974; Prockop, 1997). BMMSCs are a promising cell source for bone regeneration and immunoregulatory therapies by interacting with several subsets of immune cells (Le Blanc et al., 2004; Uccelli et al., 2007; Ren et al., 2008; Sun et al., 2009; Uccelli and Mancardi, 2010; Akiyama et al., 2012). In response to stimulation from multiple environmental factors, BMMSCs can differentiate into different lineage cells, which are regulated at both transcriptional and translational levels (Shi et al., 2002; Shi and Gronthos, 2003). In the present study, we show that Fbn1 regulates BMMSC osteogenic/adipogenic lineage selection via IL $4 \mathrm{R} \alpha / \mathrm{mTOR}$ (the mammalian target of rapamycin) signaling. Blockage of the mTOR cascade by rapamycin, an anticancer and immune suppressive drug, ameliorates the osteopenia phenotype in $\mathrm{Fbn} 1^{+/-} \mathrm{SSc}$ mice.

\section{RESULTS}

\section{Fbn 1 deficiency alters BMMSC lineage differentiation}

Because Fbn1 gene mutation leads to significant loss of bone volume and increase in BM adipocytes in B6.Cg-Fbn $1^{\text {Tsk }} / \mathrm{J}$ $\left(F b n 1^{+/-}\right)$mice (Barisic-Dujmovic et al., 2007), we hypothesize that Fbn1 deficiency may reduce osteogenic differentiation of BMMSCs and elevate their adipogenic differentiation. To test this hypothesis, we confirmed that Fbn1 deficiency resulted in an osteopenia phenotype in $\mathrm{Fbn} 1^{+/-}$mice. MicroCT and histological analysis showed that BMD, bone volume versus total volume (BV/TV), and distal femoral trabecular bone structure of $\mathrm{Fbn1}^{+/-}$mice were markedly decreased compared with the WT littermates (Fig. 1, A-D). Histomorphometric analysis revealed that the numbers of both osteoblasts and osteoclasts in the femur of $F b n 1^{+/-}$mice were significantly reduced in comparison with the WT group by alkaline phosphatase (ALP) immunohistochemical (IHC) staining and tartrate-resistant acid phosphate (TRAP) staining, respectively (Fig. 1, E and F). The level of soluble receptor activator of nuclear factor $\mathrm{\kappa B}$ ligand (sRANKL), but not osteoprotegerin (OPG), was significantly reduced (Fig. 1, G and H). In addition, we examined the in vivo function of osteoclasts and found that the serum type I collagen cross-linked telopeptide (CTX) level was significantly decreased in $F b n 1^{+/-}$mice (Fig. 1 I). These data imply that the loss of bone volume in $F b n 1^{+/-}$ mice may be mainly associated with an insufficient bone formation. To examine whether Fbn1 deficiency affects the stem cell properties of BMMSCs, we isolated BMMSCs (Fig. 2, A-C) to show that the number of colony forming unit-fibroblasts (CFU-Fs) was significantly reduced and the expression level of FBN1 was decreased in Fbn 1 ${ }^{+/-}$BMMSCs compared with the WT control (Fig. 1, J and L). The osteogenic differentiation capacity of $\mathrm{Fbn}^{+/-}$BMMSCs was decreased, as indicated by reduced mineralized nodule formation and expression of the osteogenic regulators runt-related transcription factor 2 (RUNX2), ALP, and osteocalcin (OCN; Fig. 1, K and L). Using an established in vivo BMMSC implantation assay, in which $4 \times 10^{6}$ BMMSCs with carrier hydroxyapatite tricalcium phosphate (HA/TCP) particles were subcutaneously implanted into immunocompromised mice, we showed that BMMSCs derived from $\mathrm{Fbn}^{+/-}$mice generated less bone structure than the WT group at $8 \mathrm{wk}$ after implantation (Fig. $1 \mathrm{M}$ ). To further confirm the role of Fbn 1 in BMMSC differentiation, we used siRNA to silence Fbn1 gene expression in BMMSCs (Fig. 2 D) and found a significantly reduced osteogenic differentiation, as assessed by alizarin red staining to show reduced mineralized nodule formation, immunoblotting analysis to show decreased expression of the osteogenic markers RUNX2, ALP, and OCN, and in vivo BMMSC implantation assay to show reduction in new bone formation (Fig. 1, N-P). To further confirm reduced osteogenesis in $\mathrm{Fbn}^{+/-}$mice, we performed a calcein labeling assay to show that the bone turnover rate was decreased in Fbn $1^{+/-}$mice (Fig. 1 Q). In contrast, Oil red $\mathrm{O}$ staining showed the number of adipocytes in $\mathrm{Fbn} 1^{+/-}$ BM was markedly increased when compared with the WT littermates (Fig. 2 E). To confirm that Fbn1 deficiency results in elevated adipogenesis, Fbn $1^{+/-}$BMMSCs were found to exhibit a significantly elevated number of Oil red O-positive cells and up-regulation of the adipogenic regulators peroxisome proliferator-activated receptor $\gamma 2(\operatorname{PPAR} \gamma 2)$ and lipoprotein lipase (LPL) under adipogenic culture conditions (Fig. 2, F and G). Furthermore, we showed that Fbn1-silenced BMMSCs by siRNA had a significantly increased number of Oil red $\mathrm{O}-$ positive cells and up-regulation of PPAR $\gamma 2$ and LPL (Fig. 2, $\mathrm{H}$ and I). These data suggest that Fbn1 governs osteogenic/ adipogenic lineage differentiation in BMMSCs.

\section{Fbn 1 modulates BMMSC lineage differentiation via IL4R $\alpha / m$ TOR signaling}

Because previous studies showed that $F b n 1$ mutation induced $\mathrm{T}_{\mathrm{H}} 2$ infiltration with a high level of IL4 (Gabrielli et al., 2009), we used IHC staining and ELISA to confirm a higher number of IL4-positive cells in Fbn $1^{+/-}$mouse BM and an elevated IL4 level in the peripheral blood (Fig. 3, A and B). In addition, we confirmed that $\mathrm{Fbn1}^{+/-}$mice showed significantly increased levels of $\mathrm{T}_{\mathrm{H}} 2$ cells (Fig. 3, C-F). Quantitative PCR and ELISA showed that WT and Fbn1 $1^{+/-}$BMMSCs expressed similar 

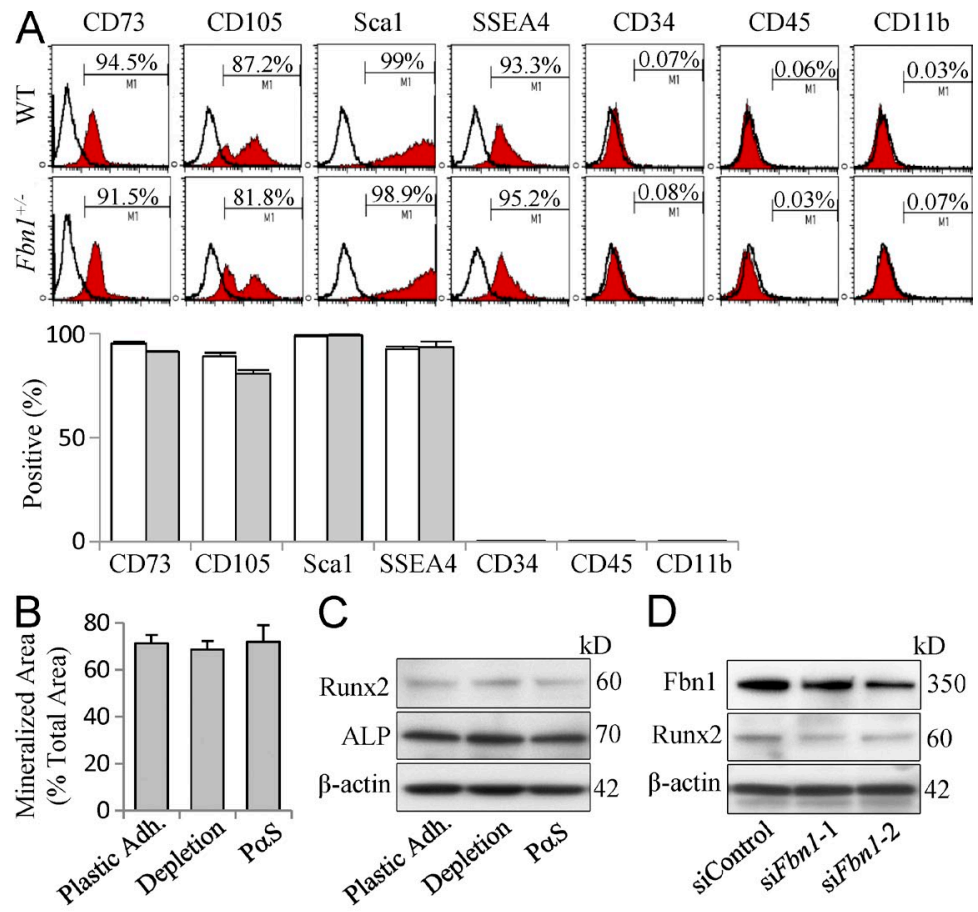

C

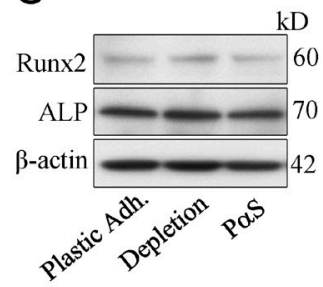

D
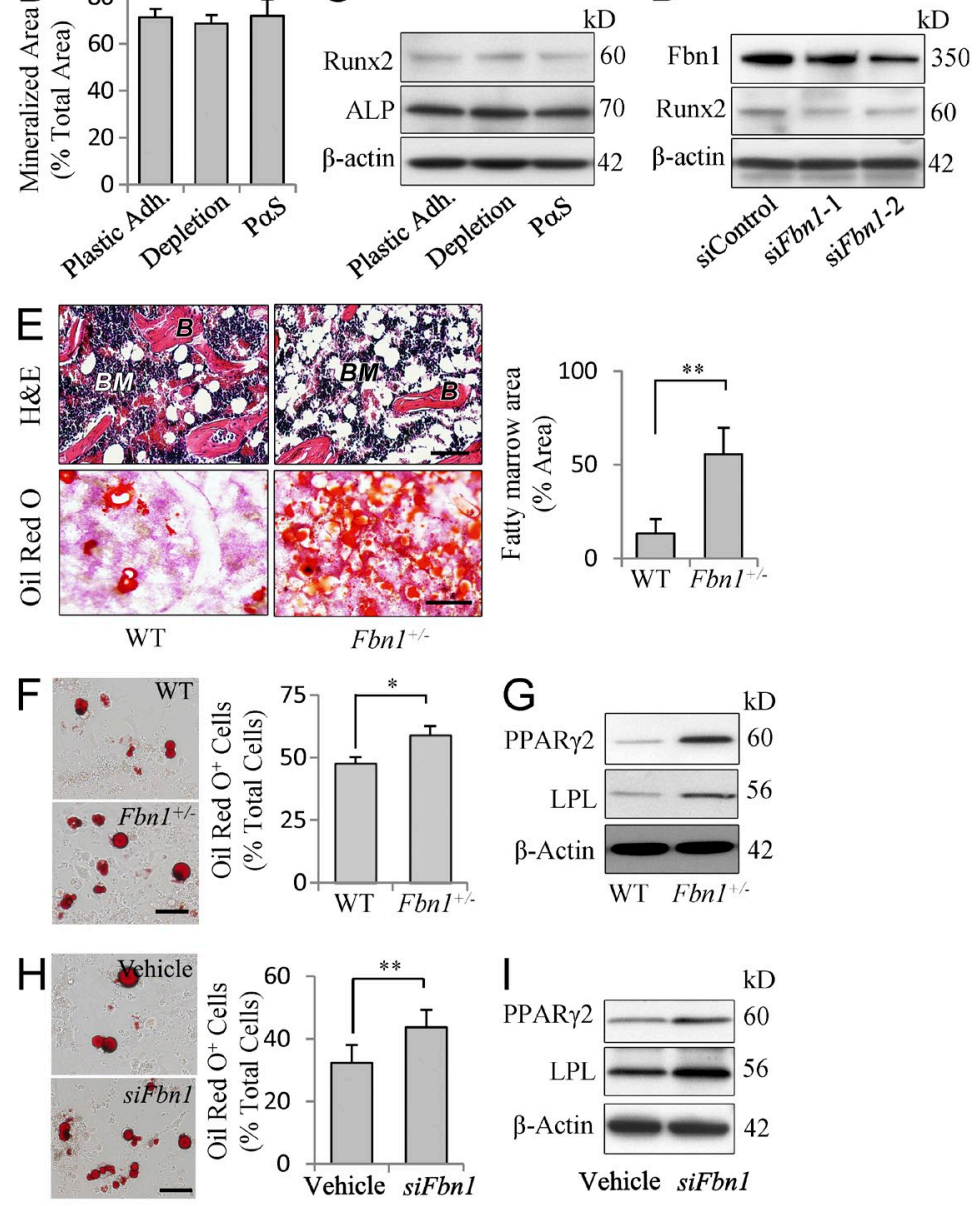

Figure 2. Fbn1-deficient BMMSCs have increased adipogenic ability. (A) Flow cytometric analysis showed the surface epitope profile of the isolated BMMSCs. (B and C) Alizarin red staining and Western blot showed the osteogenic differentiation capacities of BMMSCs derived from plastic collected single colonies, CD3 antibody/complement depletion, and flow cytometric sorting. (D) Western blot showed the efficacy of Fon 1 siRNAs in BMMSCs. (E) Histological images of distal femurs showed the number of adipocytes in WT and Fbn 1+/- mouse BM, as assessed by H\&E and Oil red 0 staining. Bars, $50 \mu \mathrm{m}$. (F) The number of Oil red $\mathrm{O}^{+}$cells in WT and Fbn 1+/- BMMSCs under adipoinductive conditions. Bar, $50 \mu \mathrm{m}$. (G) Levels of adipogenic genes PPAR 2 and LPL in WT and Fbn 1+/- BMMSCs under adipoinductive conditions. $(\mathrm{H})$ The number of Oil red $\mathrm{O}^{+}$cells in Fbn 1 siRNA knockdown BMMSCs. Bar, $50 \mu \mathrm{m}$. (I) Western blotting showed the expression levels of PPAR 2 and LPL in Fon 1 siRNA knockdown BMMSCs. All experimental data verified in at least three independent experiments. Error bars represent the SD from the mean values. ${ }^{*}, \mathrm{P}<0.05{ }^{* *}, \mathrm{P}<0.001$. low levels of IL4 (Fig. 3, G and H). Next, we examined whether activation of IL4 downstream signaling contributed to reduced osteogenesis and elevated adipogenesis in $\mathrm{Fbn} 1^{+/-}$mice. We used immunofluorescence staining to confirm that BMMSCs coexpressed the MSC marker CD73 with IL4R $\alpha$ (Fig. 3 I). Compared with control BMMSCs, Fbn $1^{+/-}$BMMSCs show up-regulated expression of IL $4 \mathrm{R} \alpha$ (Fig. $3 \mathrm{~J}$ ), which was further confirmed by qPCR analysis (Fig. $3 \mathrm{~K}$ ). Western blotting also showed that Fbn 1 deficiency up-regulated IL4R $\alpha$ downstream signaling phosphoinositide 3-kinase (PI3K)-p110, phosphorylated Akt (p-Akt), and phosphorylated mTOR (p-mTOR) in $\mathrm{Fbn}^{+/-}$BMMSCs (Fig. $3 \mathrm{~J}$ ). To verify that IL $4 \mathrm{R} \alpha / \mathrm{mTOR}$ signaling contributes to BMMSC osteo/adipo-lineage selection, we examined whether knockdown of the IL $4 \mathrm{R} \alpha / \mathrm{mTOR}$ cascade could rescue the altered lineage differentiation in Fbn $1^{+/-}$BMMSCs. Having confirmed that shRNAs could 

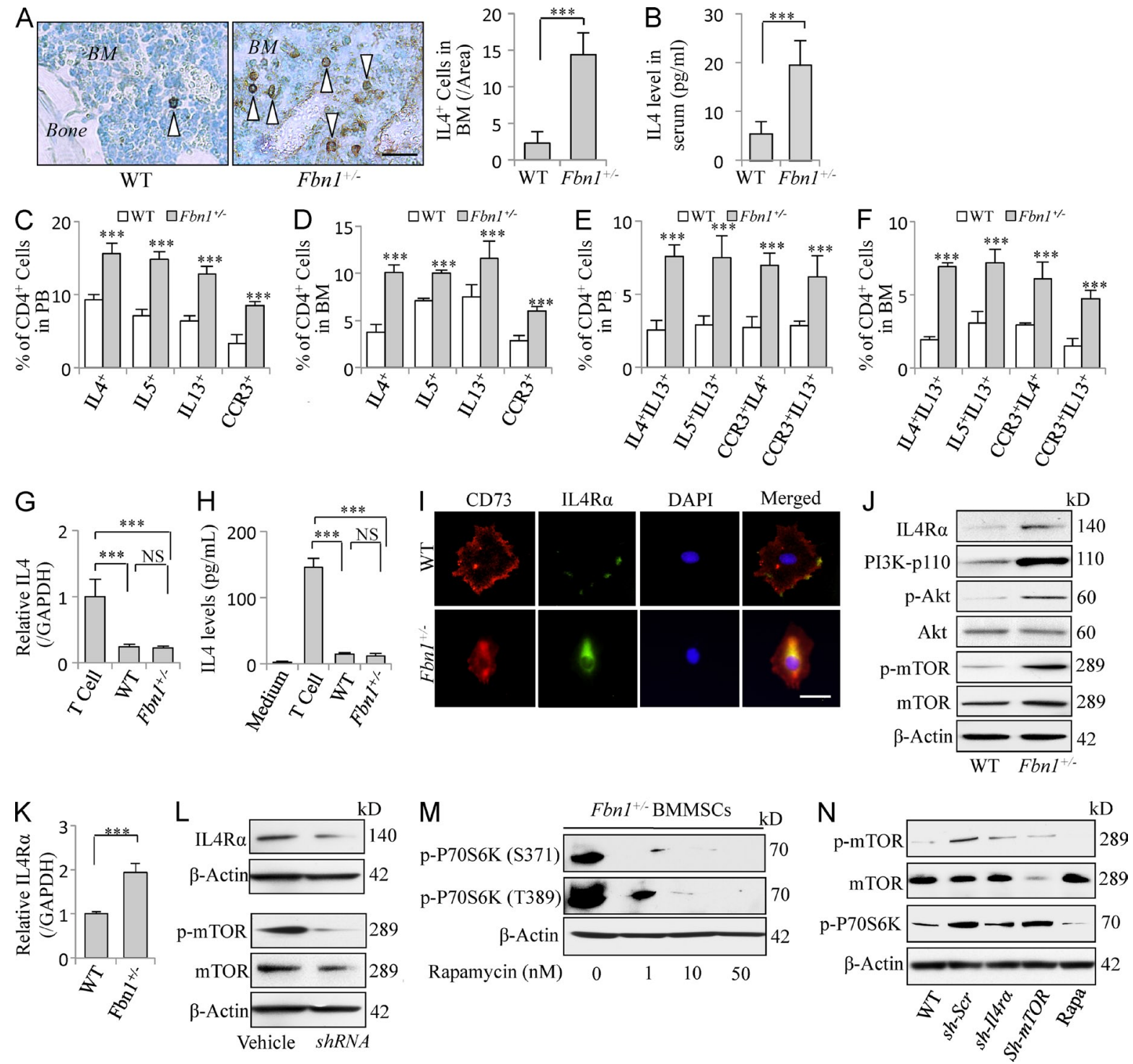

Figure 3. $\mathrm{T}_{\mathrm{H}} 2 / \mathrm{IL} 4$ infiltration in Fbn 1-deficient mice. (A) IHC staining of distal femoral in WT and Fbn $1^{+/-}$mice showed the number of IL4 $4^{+}$cells (arrowheads) in BM. Bar, $25 \mu \mathrm{m}$. (B) ELISA showed the serum level of IL4 in WT and Fbn 1+/- mice. (C-F) Flow cytometry showed $T_{H} 2$ subsets in peripheral blood (PB) and BM of WT and Fbn 1+/- mice. (G and H) qPCR and ELISA analysis showed the levels of IL4 in WT and Fbn 1+/- BMMSCs compared with T cells. (I) IF staining showed MSC marker CD73 coexpressed with IL4R $\alpha$ in WT and Fbn 1+/- BMMSCs. Bar, $25 \mu$ m. (J) Western blotting showed expression mTOR signaling genes, including IL4R $\alpha$, PI3K-p110, p-Akt, and p-mTOR in WT and Fbn 1+/- BMMSCs. (K) qPCR analysis of IL4R $\alpha$ in WT and Fbn $1^{+/-}$ BMMSCs. (L) Western blot showed efficacy of $/ / 4 r \alpha$ and mTOR shRNAs in Fbn $1^{+1-}$ BMMSCs. (M) Western blot showed that rapamycin treatment induced a dose-dependent inhibition of p-P70S6K in Fbn 1+/- BMMSCs. (N) Western blot showed the expression levels of p-mTOR and p-P70S6K in shRNAs and rapamycin-treated $\mathrm{Fbn} 1^{+-}$BMMSCs. Shown are representative of all experimental data verified in at least three independent experiments. Error bars represent the SD from the mean values. ${ }^{* *}, \mathrm{P}<0.005$.

knock down Il $4 r \alpha$ and $m$ TOR (Fig. $3 \mathrm{~L}$ ) and that rapamycin treatment could inhibit mTOR signaling in a dose-dependent manner (Fig. $3 \mathrm{M}$ ), we showed that Il $4 r \alpha$ and $m$ TOR shR$\mathrm{NAs}$, as well as rapamycin treatment, significantly improved osteogenic differentiation of $\mathrm{Fbn} 1^{+/-}$BMMSCs, as indicated by alizarin red staining to show increased mineralized nodule formation, Western blotting to show elevated expression of the RUNX2, ALP, and OCN, and in vivo BMMSC implantation assay to show increased new bone formation at $8 \mathrm{wk}$ after implantation (Fig. 4, A-C). Conversely, the elevated adipogenic differentiation in $\mathrm{Fbn} 1^{+/-}$BMMSCs was significantly reduced in the shRNAs or rapamycin treatment groups, as indicated by a decreased number of Oil red $\mathrm{O}-$ positive cells and down-regulation of the PPAR $\gamma 2$ and LPL (Fig. 4 D). To avoid off-target effect, we used IL4R $\alpha$ neutralizing antibody to block IL4 signaling and found decreased expression of p-mTOR and elevated expression of RUNX2 in $\mathrm{Fbn1}^{+/-}$ BMMSCs when compared with control group (Fig. 4 E). We next revealed that mTOR regulated osteogenic differentiation of $\mathrm{Fbn}^{+/-}$BMMSCs through its downstream signaling 

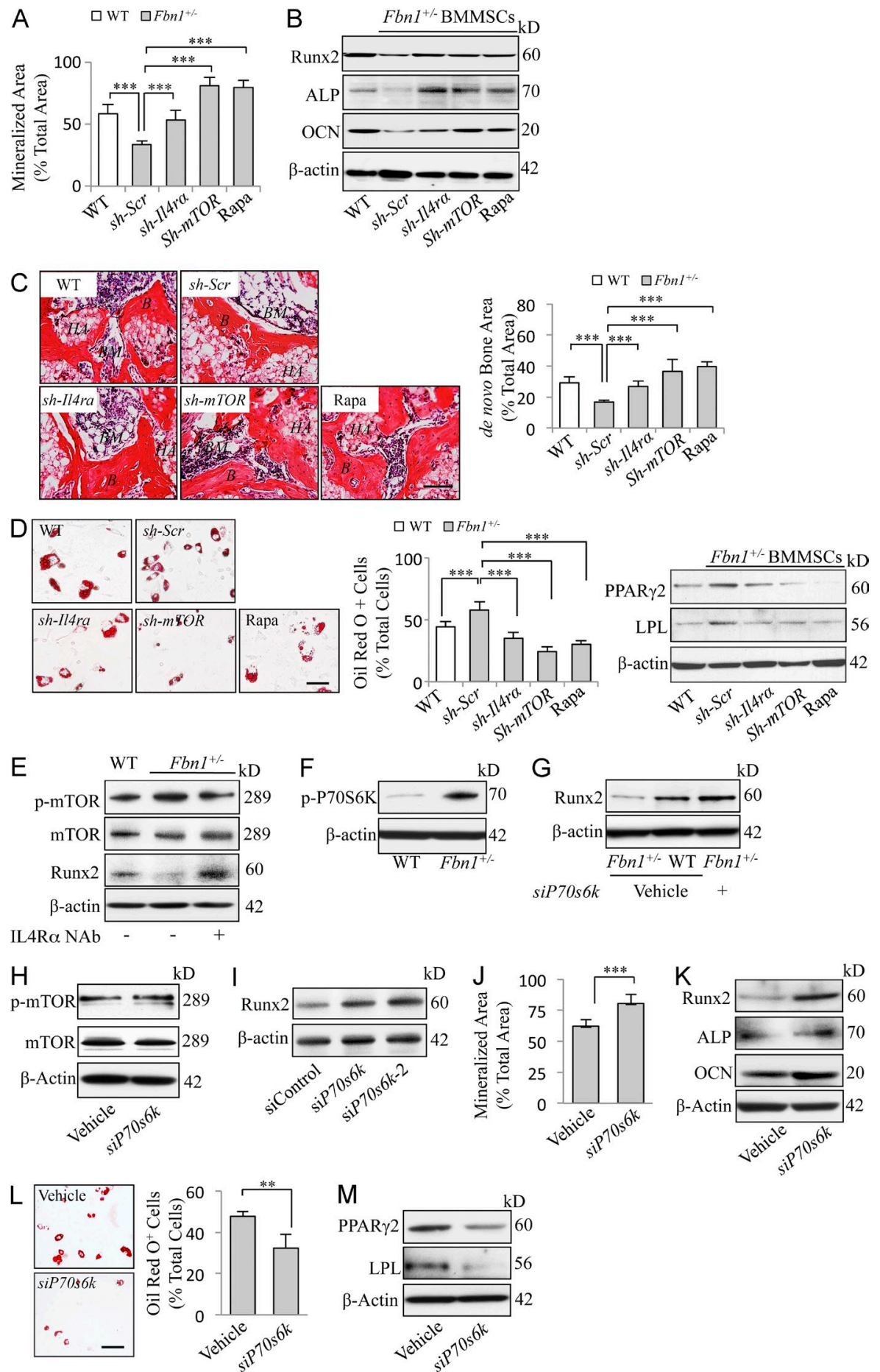

phosphorylated P70 ribosomal S6 protein kinase (P70S6K). Western blot analysis showed that p-P70S6K expression level was increased in Fbn $1^{+/-}$BMMSCs (Fig. 4 F). When p-mTOR expression was knocked down by Il $4 r \alpha$ and $m$ TOR shRNAs, or rapamycin treatment, in $\mathrm{Fbn} 1^{+/-}$BMMSCs, a corresponding down-regulation of $\mathrm{p}-\mathrm{mTOR}$ and $\mathrm{p}-\mathrm{P} 70 \mathrm{~S} 6 \mathrm{~K}$ was revealed by Western blot analysis (Fig. $3 \mathrm{~N}$ ). Although knockdown of P70s6k expression by siRNA in Fbn $1^{+/-}$BMMSCs resulted in up-regulation of RUNX2 expression (Fig. 4 G), the expression
Figure 4. Fbn 1 deficiency-induced activation of IL $4 R \alpha / m T O R$ signaling regulates osteogenic/adipogenic lineage differentiation of BMMSCs. (A) Alizarin red staining showed the capacity to form mineralized nodules in scrambled shRNA (sh-Scr)-treated, $\| 4 r \alpha$, and $m T O R$ shRNA- and rapamycintreated Fbn 1+/- BMMSCs. (B) Western blot showed the expression of the osteogenic genes RUNX2, ALP, and OCN in Fbn 1+/BMMSCs with shRNAs and rapamycin treatment. (C) H\&E staining showed BMMSCmediated bone $(\mathrm{B})$ and $\mathrm{BM}$ regeneration when subcutaneously implanted into immunocompromised mice with $\mathrm{HA}$ carrier after shRNAs and rapamycin treatment in Fbn $1^{+1-}$ BMMSCs. Bars, $50 \mu \mathrm{m}$. A semiquantitative analysis showed the amount of bone formation in different implants. (D) Oil red 0 staining showed the capacity to differentiate into adipocytes in shRNAs and rapamycin-treated Fon $1^{+1-}$ BMMSCs, as well as the expression levels of adipogenic genes PPAR $\gamma 2$ and LPL. Bar, $50 \mu \mathrm{m}$. (E) IL4R $\alpha$ neutralizing antibody (NAb) treatment showed the expression levels of p-mTOR and RUNX2 in Fbn 1+/- BMMSCs.

(F) Western blot showed the level of p-P70S6K in Fbn 1+/- BMMSCs. (G) Western blot showed the expression level of RUNX2 in Fbn 1+/- BMMSCs after knockdown of P70s6k by siRNA. (H) Western blot analysis showed the expression of $p$-mTOR after knockdown of P70s6k. (I) To avoid off-target effects, two P70s6k siRNAs were used to show they both elevated expression of RUNX2 in Fbn 1+/BMMSCs. (J-M) Knockdown of P70s6k by siRNA, Fbn 1+/- BMMSCs showed increased mineralized nodule formation by alizarin red staining $(\mathrm{J})$, elevated expression of RUNX2, $A L P$, and OCN $(K)$, decreased Oil red $0^{+}$cells (bar, $50 \mu \mathrm{m} ; \mathrm{L}$ ), and decreased expression of PPAR 2 and LPL (M). All experimental data verified in at least three independent experiments. Error bars represent the SD from the mean values. ${ }^{* * *}, P<0.005 ;{ }^{* *}, P<0.01$. levels of mTOR was unaffected (Fig. $4 \mathrm{H}$ ). To avoid off-target effects, a second P70s6k siRNA was used to show elevated expression of RUNX2 (Fig. 4 I). In addition, the osteogenic differentiation was markedly increased in P70s6k knockdown $\mathrm{Fbn1}^{+/-}$BMMSCs, as indicated by elevated mineralized nodule formation (Fig. $4 \mathrm{~J}$ ) and expression of the RUNX2, ALP, and OCN (Fig. 4 K). In contrast, the number of Oil red Opositive cells (Fig. $4 \mathrm{~L}$ ) and the expression levels of the adipogenic genes were significantly down-regulated (Fig. 4 M), 
A

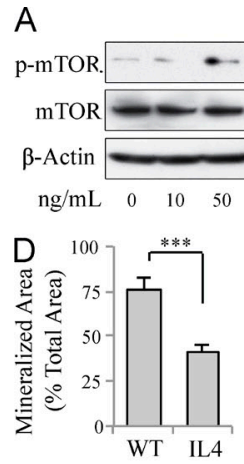

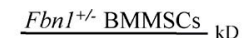
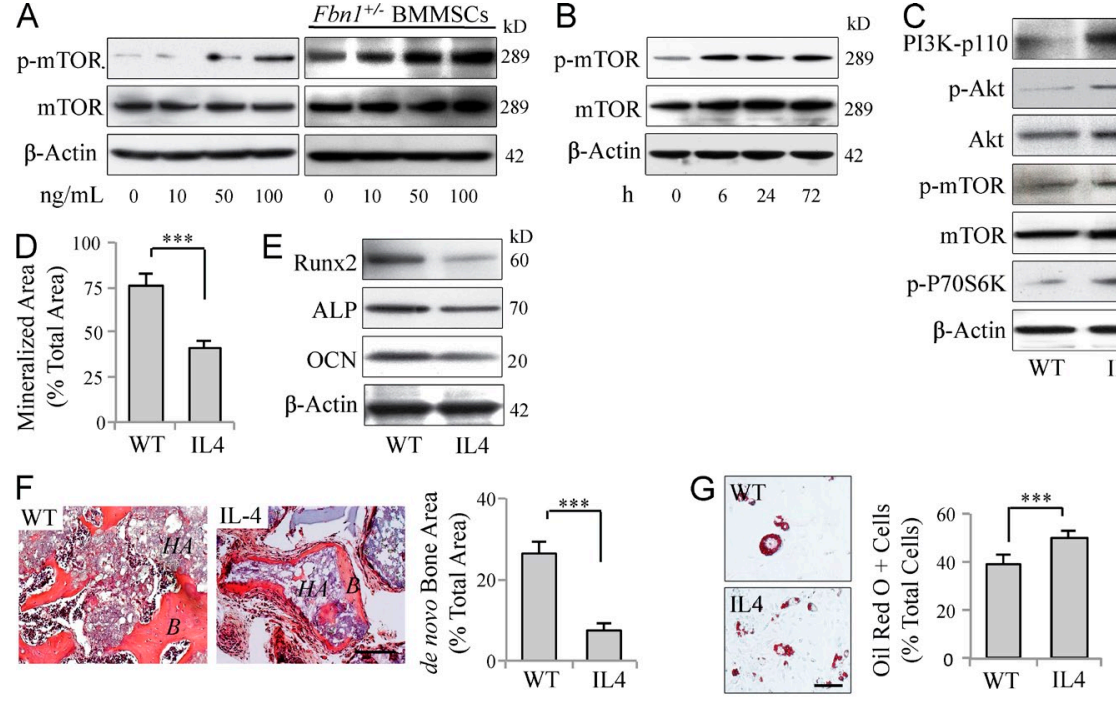

Figure 5. IL4/mTOR signaling governs lineage commitment of BMMSCs.

(A) Western blot showed that IL4 treatment resulted in elevated expression of $p-m T O R$ in an dose-dependent manner in WT and Fon $1^{+/-}$BMMSCs. (B) Western blot showed IL4 treatment resulted in elevated $p$-mTOR expression starting at $6 \mathrm{~h}$ after treatment and lasting until $72 \mathrm{~h}$ after treatment in WT BMMSCs. (C) Western blot showed the expression of mTOR signaling, including PI3K-p110, p-Akt, $p-m T O R$, and $p$-P7OS6K in IL4-treated BMMSCs. (D) Alizarin red staining showed BMMSC-mediated mineralized nodule formation after mTOR activation. (E) Western blot indicated the expression of osteogenic genes RUNX2, ALP, and OCN in BMMSCs after mTOR activation. (F) H\&E staining showed the capacity to form bone in mTOR-activated BMMSCs when implanted into immunocompromised mice. Bar, $50 \mu \mathrm{m}$. A semiquantitative analysis showed the amount of bone formation in implants. (G) Oil red 0 staining showed the number of adipocytes in mTORactivated BMMSCs. Bar, $50 \mu \mathrm{m}$. (H) Western blot showed the expression of adipogenic genes PPAR 2 and LPL in mTOR-activated BMMSCs. (I) Western blot showed the expression levels of $\mathrm{p}$-Rictor and $\mathrm{p}$-Raptor in $\mathrm{Fbn}^{+/-}$ BMMSCs. (J) Western blot showed the expression of osteogenic marker RUNX2 in Fbn $1^{+/-}$ BMMSCs after siRNA knockdown of either Rictor or Raptor. (K) Western blotting analysis showed that knockdown of Rictor resulted in

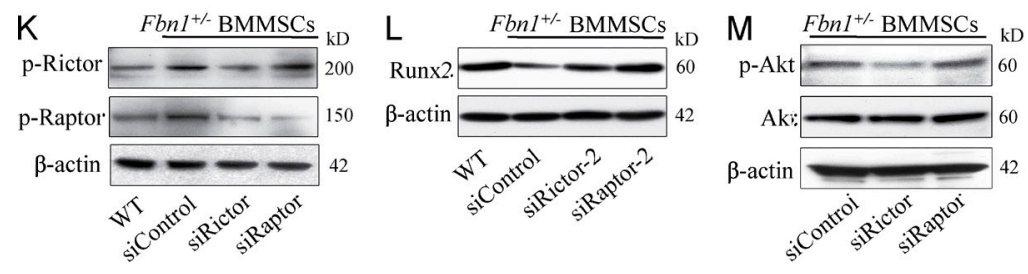
down-regulation of both Raptor and Rictor, whereas knockdown of Raptor resulted in only down-regulation of Raptor. (L) To avoid off-target effects,
second TORC1 or TORC2 siRNAs were used to show elevated expression of RUNX2 in BMMSCs. (M) Western blot showed that knockdown of Rictor, but not Raptor, resulted in down-regulation of p-Akt. All experimental data verified in at least three independent experiments. Error bars represent the SD from the mean values. ${ }^{* *}, P<0.005$.

suggesting that mTOR regulates P70S6K to control RUNX2mediated osteogenic differentiation and PPAR $\gamma 2$-mediated adipogenic differentiation.

To further confirm that the IL4-IL4R $\alpha$ pathway activates mTOR signaling, we performed a dosage and kinetics analysis to show that IL4 at a concentration of $50-100 \mathrm{ng} / \mathrm{ml}$ is able to activate $\mathrm{mTOR}$ signaling in WT BMMSCs and the activation of mTOR signaling can occur as earlier as $6 \mathrm{~h}$ after IL4 treatment (Fig. 5, A and B). When treated with IL4, Fbn 1 ${ }^{+/-}$BMMSCs exhibited a more significant increase in the expression of $\mathrm{p}-\mathrm{mTOR}$ than the control BMMSCs (Fig. 5 A). Western blot analysis confirmed up-regulation of mTOR downstream signaling including PI3K, p-Akt, p-mTOR, and p-P70S6K (Fig. 5 C). Furthermore, we showed that IL4 treatment-activated mTOR signaling inhibited osteogenic differentiation of WT BMMSCs, as indicated by reduced mineralized nodule formation, decreased expression of the RUNX2, ALP, and OCN, and reduced bone formation when subcutaneously implanted into immunocompromised mice (Fig. 5, D-F), along with elevated adipogenic differentiation, as indicated by the increased number of Oil red
O-positive cells and the expression of PPAR $\gamma 2$ and LPL (Fig. 5, $\mathrm{G}$ and $\mathrm{H}$ ). These data suggest that activation of the IL4/IL4R $\alpha$ / mTOR/P70S6K cascade contributes to osteogenic deficiency of $\mathrm{Fbn}^{+/-}$BMMSCs and that blockade of mTOR signaling may be a promising therapeutic approach for rescuing osteogenic deficiency in $\mathrm{Fbn}^{+/-}$mice.

Because mTOR signaling involves two complexes, namely mTOR complex 1 (TORC1) and complex 2 (TORC2), we next examined which mTOR complex plays a functional role in regulating $\mathrm{Fbn1^{+/ }}$ BMMSC differentiation. We found that Fbn 1+/- BMMSCs expressed elevated levels of mTOR/ Raptor/TORC1 and mTOR/Rictor/TORC2 when compared with the control group (Fig. 5 I). When using siRNA to knockdown either TORC1 or TORC2, the expression of the osteogenic marker Runx2 was up-regulated in $F b n 1^{+/-}$ BMMSCs (Fig. $5 \mathrm{~J}$ ). Knockdown of TORC2 resulted in downregulation of both Raptor and Rictor, whereas knockdown of TORC1 only resulted in down-regulation of Raptor (Fig. $5 \mathrm{~K}$ ), suggesting that TORC2 may act upstream of TORC1. To avoid off-target effects, we used secondary TORC1 and TORC2 

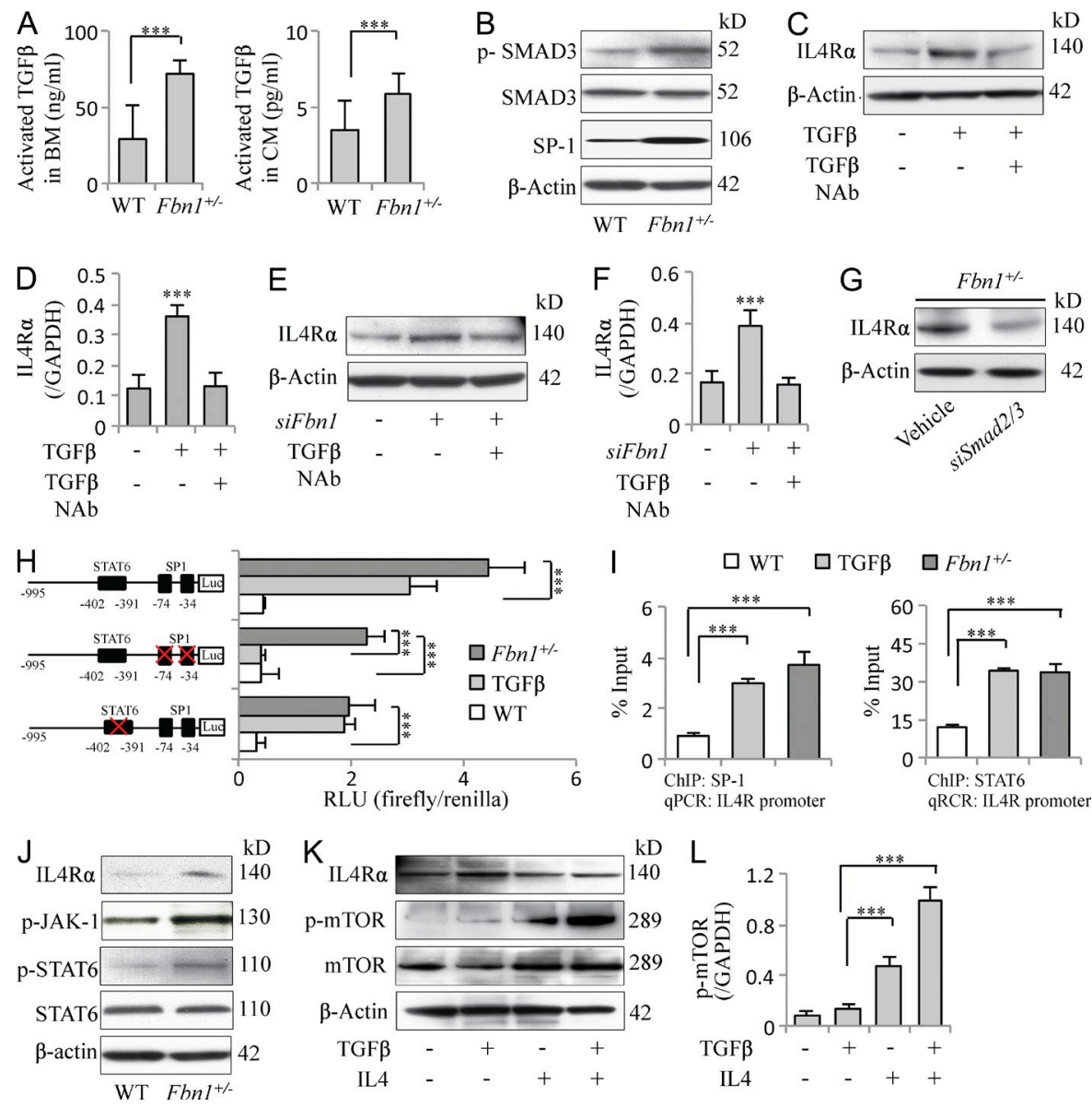

Figure 6. TGF- $\beta$ and STAT6 synergistically enhance the expression of IL4R $\alpha$ in $\mathrm{Fbn}^{+/-}$BMMSCs. (A) ELISA assay showed the level of TGF- $\beta$ in Fbn $1^{+/-}$mouse serum and Fbn 1+/- BMMSCs cultured medium compared with WT group. (B) Western blotting showed the expression levels of p-SMAD3 and SP-1 in WT and Fbn $1^{+-}$BMMSCs. (C and D) Western blotting showed that TGF- $\beta$ treatment elevated IL4R $\alpha$ expression in BMMSCs, which could be blocked by TGF- $\beta$ neutralizing antibody (NAb). (E and F) Western blot showed that Fon 1 knockdown by siRNA in BMMSCs elevated IL4R $\alpha$ expression, which could be blocked by TGF- $\beta$ NAb. (G) Western blot showed the expression of IL $4 R \alpha$ after Smad2/3 siRNA treatment compared with vehicle-treated group. $(\mathrm{H}) / / 4 r \alpha$ promoter luciferase fusions were examined in WT, TGF$\beta$-treated, and Fbn 1+/- BMMSCs. Promoter activity was expressed as relative light units (RLU) normalized to the activity of cotransfected Renilla luciferase. (I) ChIP-qPCR assay showed enrichment of direct association of SP1 and STAT6 on $/ / 4 r \alpha$ promoter in TGF$\beta$-treated and Fbn 1+/- BMMSCs. (J) Western blot showed the expression of p-JAK1 and p-STAT6 in Fon $1^{+/-}$BMMSCs. (K and L) Western blotting showed the expression of IL4R $\alpha$ and p-mTOR after TGF- $\beta$, IL4, or combinatorial treatment with TGF- $\beta$ and IL4. All experimental data verified in at least three independent experiments. Error bars represent the SD from the mean values. ${ }^{* *}, \mathrm{P}<0.005$.
siRNAs to show they are able to elevate expression of RUNX2 in Fbn $1^{+/-}$BMMSCs (Fig. 5 L). Because Akt is a downstream target of TORC2, we examined the expression levels of $\mathrm{p}$-Akt after the knockdown of either TORC1 or TORC2 and confirmed that TORC2 acted upstream of TORC1 through the Akt cascade in $\mathrm{Fbn1}^{+/-}$BMMSCs (Fig. $5 \mathrm{M}$ ).

\section{IL4R $\alpha$ is activated by the TGF- $\beta$ pathway in Fbn 1-deficient BMMSCs}

It was reported that FBN1 interacts with LTBP-1 to bind TGF- $\beta$ (Charbonneau et al., 2004; Ramirez and Sakai, 2010). As such, Fbn1 deficiency causes an increased release of TGF- $\beta$ to the skin and lung (Gabrielli et al., 2009; Holm et al., 2011). We examined the level of TGF- $\beta$ in $\mathrm{Fbn}^{+/-}$mouse BM and Fbn $1^{+/-}$BMMSC culture medium and found that both BM and medium contained elevated levels of TGF- $\beta$, as assessed by ELISA assay (Fig. 6 A). Next, we used Western blotting to confirm that TGF- $\beta$ downstream signaling $\mathrm{p}-\mathrm{SMAD} 3$ and SMAD-associated transcription factor SP1 (Docagne et al., 2004; Jungert et al., 2006) were significantly increased in $\mathrm{Fbn}^{+/-}$ BMMSCs compared with the control BMMSCs (Fig. 6 B). To further confirm that Fbn1 deficiency-mediated IL4R $\alpha$ expression occurs through TGF- $\beta$ release, we treated BMMSCs with recombinant TGF- $\beta 1$ or Fbn 1 siRNA, followed by TGF- $\beta$ neutralizing antibody blocking. Western blot analysis revealed that both TGF- $\beta 1$ and Fbn 1 siRNA treatment increased IL4R $\alpha$ levels, which could be blocked by TGF- $\beta$ neutralizing antibody treatment (Fig. 6, C-F). To further confirm that TGF- $\beta$ signaling activates IL4R $\alpha$ expression, we used siRNA to block canonical TGF- $\beta$ pathway and then examine the expression level of IL4R $\alpha$ in Fbn $1^{+/-}$BMMSCs. Western blot analysis showed that IL $4 \mathrm{R} \alpha$ was significantly decreased in $\mathrm{Fbn} 1^{+/-}$ BMMSCs after Smad2/3 siRNA treatment (Fig. 6 G), indicating that TGF- $\beta /$ SMAD3 signaling may directly regulate IL4R $\alpha$ expression. To determine whether increased expression of IL4R $\alpha$ in Fbn $1^{+/-}$BMMSCs is attributed to the TGF- $\beta$ / SMAD3 signaling, we generated an Il4r $\alpha$ promoter reporter construct in which the defined region of the Il $4 r \alpha$ promoter and flanking region were placed upstream of a reporter gene encoding firefly luciferase. We used BIOBASE biological databases to search the Il $4 r \alpha$ promoter sequence and found two SP1 and one STAT6 candidate sites, which were closely matching with the SMAD3-associated SP1 and IL4R $\alpha$ downstream STAT6 transcription factors consensus targets (Fig. $6 \mathrm{H}$ ). We next demonstrated that Il $4 r \alpha$ promoter activity was markedly induced in both $\mathrm{Fbn}^{+/-}$and TGF- $\beta$-treated BMMSCs. When $F b n 1^{+/-}$BMMSCs were transfected with reporter vector, the luciferase assay showed a significantly increased $I l 4 r \alpha$ promoter 

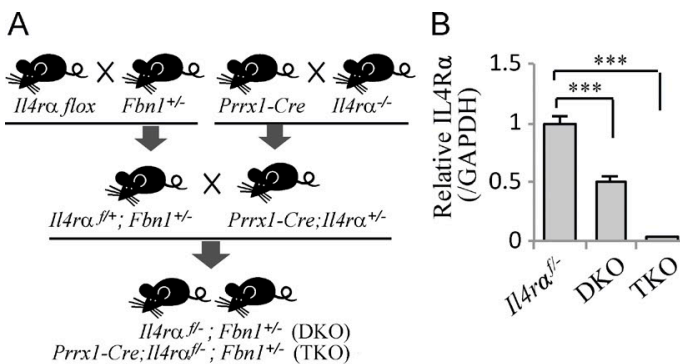
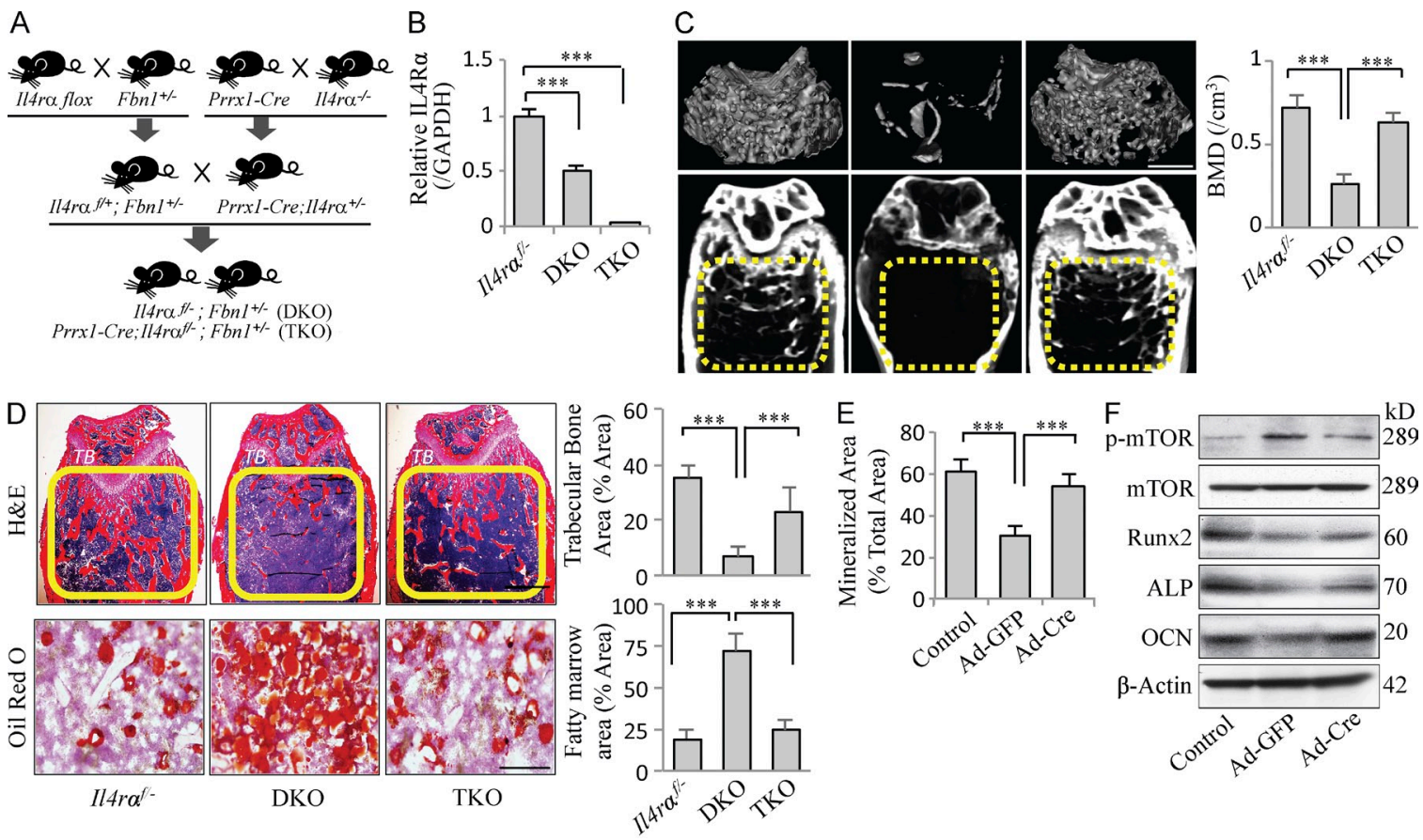

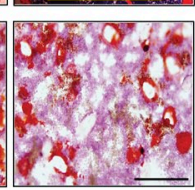

TKO

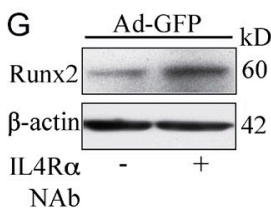

DKO

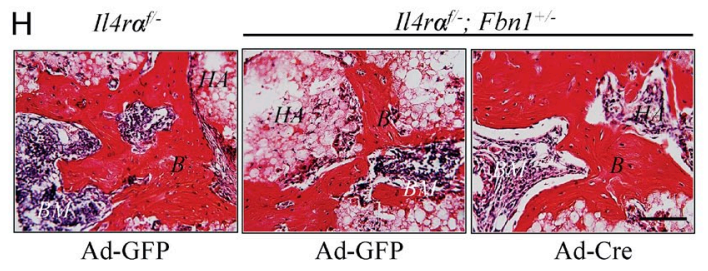

Ad-GFP

Ad-GFP
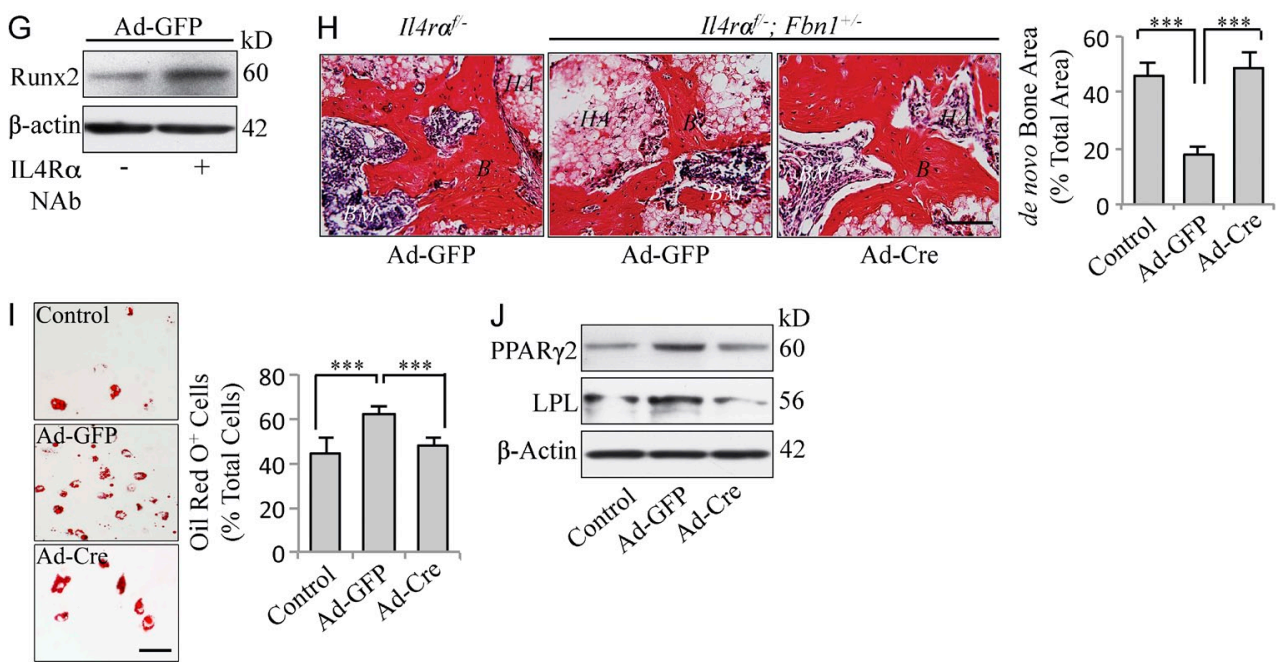

Figure 7. Conditional KO of IL4R $\alpha$ in BMMSC ameliorates osteopenia phenotype by rescuing impaired osteogenic/adipogenic differentiation. (A) Experimental outline describing the use of $\| / 4 r \alpha^{f / f}$ crossed with Fbn $1^{+/-}$mice to generate $/ / 4 r \alpha^{f /+} ; F b n 1^{+/-}$mice. Prrx 1 -Cre mice were crossed with

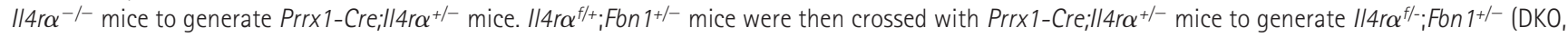

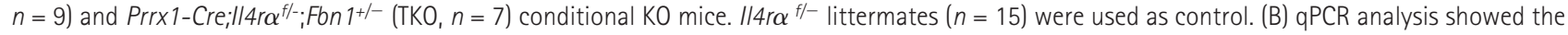
efficacy of Cre-medicated deletion of the floxed allele. (C) MicroCT analysis showed the BMD of DKO and TKO mice. Bar, $1 \mathrm{~mm}$. (D) H\&E (bar, $1 \mathrm{~mm}$ ) and Oil red $O($ bar, $50 \mu \mathrm{m})$ staining showed the $T B$ volume and percentage of adipocytes in distal femur. (E) Alizarin red staining showed the mineralized nodule forming capacity in Adenovirus-Cre-treated BMMSCs derived from DKO mice (Ad-Cre) compared with Adenovirus-GFP-treated DKO group (Ad-GFP). (F) Western blot analysis showed the expression of p-mTOR, RUNX2, ALP, and OCN in Ad-Cre compared with Ad-GFP. (G) Western blot showed the expression of RUNX2 in IL4R $\alpha$ NAb-treated DKO BMMSCs. (H) When implanted into immunocompromised mice subcutaneously with HA carrier, Ad-Cre showed significantly increased bone formation. Bar, $50 \mu \mathrm{m}$. (I) Oil red 0 staining showed the number of adipocytes in Ad-Cre. Bar, $50 \mu \mathrm{m}$. (J) Western blotting showed the expression of adipogenic genes PPAR 2 and LPL in Ad-Cre. All experimental data verified in at least three independent experiments. Error bars represent the SD from the mean values. ${ }^{* *}, \mathrm{P}<0.005$.

activity. Introduction of SP1 mutated reporter vector markedly diminished the expression of the $I l 4 r \alpha$-luciferase reporter in both $\mathrm{Fbn1}^{+/-}$and TGF- $\beta$-treated BMMSCs, indicating the direct initiation of IL4R $\alpha$ expression by TGF- $\beta-$ SMAD3-SP1 cascades (Fig. $6 \mathrm{H}$ ). We next determined whether SP1 regulates Il $4 r \alpha$ promoter in BMMSCs. Using chromatin immunoprecipitation (ChIP), the SP1 binding consensus sequence within the promoter region was examined to confirm its ability to 
A

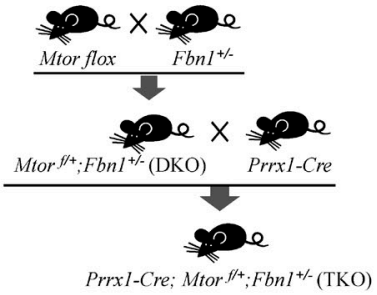

B

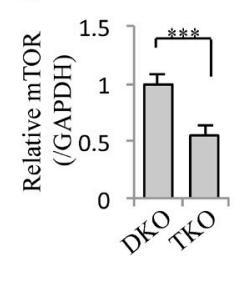

C

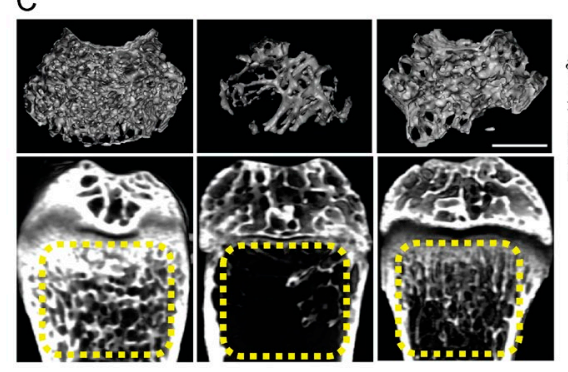

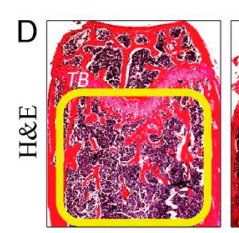
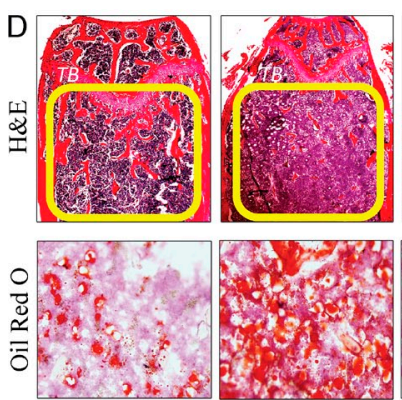

Mtorf +

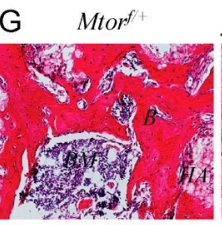

Ad-GFP

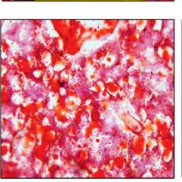

DKO

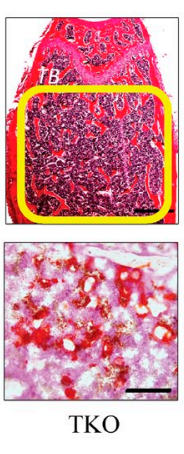

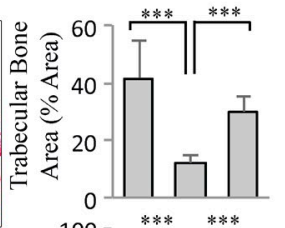
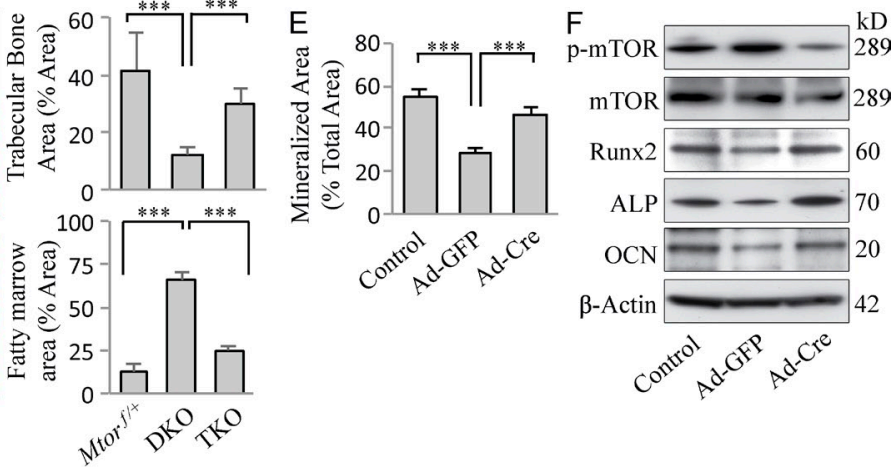

(110)
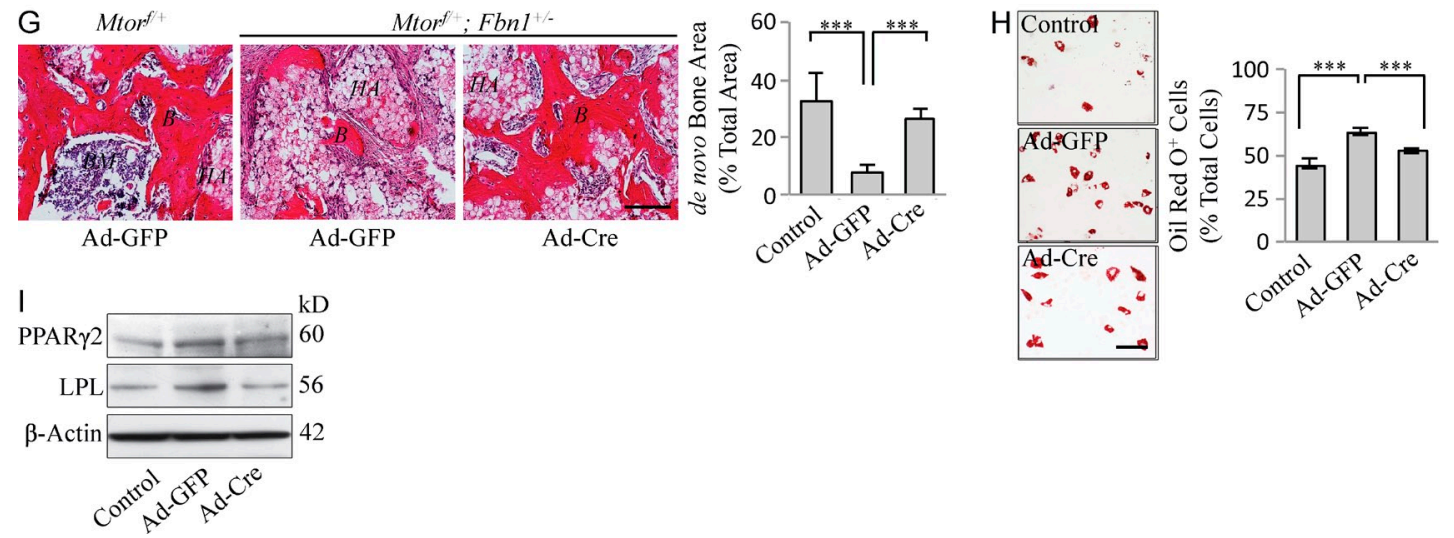

Figure 8. Conditional KO of $m T O R$ in BMMSC ameliorates osteopenia phenotype by rescuing impaired osteogenic/adipogenic differentiation. (A) Experimental outline describing the generation of $\mathrm{Mtor}^{\mathrm{fl} /} ; \mathrm{Fbn} \mathrm{1}^{+-}(\mathrm{DKO}, n=8)$ and Prrx 1-Cre;Mtorf/+Fon ${ }^{+/-}(\mathrm{TKO}, n=6)$ mice. (B) qPCR analysis showed the efficacy of Cre-medicated deletion of the floxed allele. (C) MicroCT analysis showed the BMD of DKO and TKO mice. Bar, $1 \mathrm{~mm}$. (D) H\&E (bar, $1 \mathrm{~mm}$ ) and Oil red $\mathrm{O}(\mathrm{bar}, 50 \mathrm{\mu m}$ ) staining showed the TB volume and adipocytes in distal femur of DKO and TKO mice. (E) Alizarin red staining showed the mineralized nodule formation in Ad-Cre. (F) Western blotting showed the expression levels of p-mTOR, RUNX2, ALP, and OCN in Ad-Cre and Ad-GFP. (G) When implanted into immunocompromised mice with $H A$ carrier, Ad-Cre showed significantly increased bone formation. Bar, $50 \mu \mathrm{m}$. (H) Quantitative analysis showed the number of Oil red $0^{+}$cells in Ad-Cre. Bar, $50 \mu$ m. (I) Western blotting showed the expression of adipogenic genes PPAR 2 and LPL in Ad-Cre compared with Ad-GFP. All experimental data verified in at least three independent experiments. Error bars represent the SD from the mean values. ${ }^{* *}, \mathrm{P}<0.005$.

recruit SP1. As expected, SP1-bound DNA at the candidate site was significantly enriched in TGF- $\beta$-treated BMMSCs and Fbn $1^{+/-}$BMMSCs (Fig. 6 I), suggesting that TGF- $\beta$ may act as an initiator to elevate IL4R $\alpha$ expression. In parallel, we used a ChIP-qPCR assay and found that STAT6 directly bound to the predicted promoter region of Il $4 r \alpha$ and that STAT6 recruitment was enriched at the Il $4 r \alpha$ promoter in $\mathrm{Fbn}^{+/-}$or TGF- $\beta$-treated BMMSCs (Fig. 6 I). Western blot analysis further confirmed that an IL4R $\alpha$-JAK1-STAT6 cascade was activated in $\mathrm{Fbn}^{+/-}$BMMSCs, as shown by up-regulation of p-JAK1 and p-STAT6 expression (Fig. $6 \mathrm{~J}$ ). These results prompted us to examine whether STAT6 induced IL4R $\alpha$ expression at the transcriptional level using a promoter reporter assay. Control BMMSCs, TGF- $\beta$-treated BMMSCs, and $\mathrm{Fbn}^{+/-}$BMMSCs were transfected with a reporter vector or STAT6 candidate site mutated reporter vector, followed by luciferase assay. TGF- $\beta$-treated and Fbn $1^{+/-}$BMMSCs showed increased promoter activity in comparison to control BMMSCs. Introduction of STAT6 mutated reporter vector markedly diminished the expression of the Il $4 r \alpha$-luciferase reporter in $\mathrm{Fbn}^{+/-}$BMMSCs, but not TGF- $\beta$-treated BMMSCs. Thus, TGF- $\beta$ may act as an initiator to elevate IL4R $\alpha$ expression, and TGF- $\beta$-activated IL $4 \mathrm{R} \alpha$ is independent from IL $4 \mathrm{R} \alpha-$ STAT6 cascades (Fig. $6 \mathrm{H}$ ). These results prompted us to 
examine whether TGF- $\beta$ and IL4 synergistically activate the mTOR signaling in BMMSCs. We found that TGF- $\beta$, but not IL4, treatment elevated the expression levels of IL4R $\alpha$ in BMMSCs by Western blot analysis (Fig. 6, K and L). Although TGF- $\beta$ and IL4 treatments each elevated expression levels of $\mathrm{p}-\mathrm{mTOR}$ in BMMSCs, combinatorial treatment of TGF- $\beta$ and IL4 resulted in a marked increase in $\mathrm{p}-\mathrm{mTOR}$ expression (Fig. 6, K and L). These results indicate that the Fbn 1 deficiency-induced TGF- $\beta$-SMAD3-SP1/IL4R $\alpha$ cascade synergistically enhances mTOR signaling with STAT6 signaling in $\mathrm{Fbn1}^{+/-}$BMMSCs at the transcriptional level, which leads to lineage alteration of $\mathrm{Fbn}^{+/-}$BMMSC.

\section{Conditional knockdown of IL4R $\alpha / m T O R$ in BMMSCs/osteoblasts or rapamycin treatment ameliorates osteopenia phenotype in $\mathrm{Fbn}^{+/-}$mice}

Because IL4R $\alpha / m$ TOR alters BMMSC lineage commitment, depletion of mTOR expression in BMMSC lineage may serve as a key approach to recover Fbn 1 deficiency-induced osteopenia. To achieve such a tissue-specific $\mathrm{KO}$, we first generated Prrx1-Cre;Il4r $\alpha^{f /-} ; F_{b n} 1^{+/-}$triple conditional KO (TKO) mice to $\mathrm{KO}$ IL $4 \mathrm{R} \alpha$ in $\mathrm{Fbn}^{+/-}$BMMSCs (Fig. $7 \mathrm{~A}$ ). Il $4 \mathrm{r} \alpha^{f /-}$ littermates were used as normal control, and $I l 4 r \alpha^{f /-} ; F b n 1^{+/-}$ (DKO) littermates were used as osteopenia models (Fig. 7 A). The efficacy of Cre-medicated deletion of floxed alleles was shown by qPCR analysis (Fig. 7 B). MicroCT analysis showed that TKO mice have significantly increased BMD compared with $\mathrm{DKO}$ mice, indicating that Il4r $\alpha$ conditional $\mathrm{KO}$ rescued BMD in Fbn 1 deficiency-induced osteopenia (Fig. 7 C). Histological analysis showed that trabecular bone volume in TKO mice was increased compared with the DKO mice (Fig. 7 D). The numbers of adipocytes in TKO mouse BM were significantly reduced when compared with the DKO mice, as assessed by Oil red $\mathrm{O}$ staining (Fig. $7 \mathrm{D}$ ). To investigate the role of IL $4 \mathrm{R} \alpha$ in the differentiation of $\mathrm{Fbn}^{+/-}$BMMSCs, we isolated BMMSCs from DKO mice and knocked down Il4ro using an adenovirus expressing Cre with GFP (Ad-Cre-DKOBMMSCs) or an adenovirus expressing GFP only (Ad-GFPDKO-BMMSCs) as a control.Ad-Cre-DKO-BMMSCs showed significantly increased osteogenic differentiation, as assessed by alizarin red staining indicating elevated mineralized nodule formation (Fig. 7 E); Western blotting indicating rescued expression of the $\mathrm{mTOR} /$ osteogenic cascade genes $\mathrm{p}-\mathrm{mTOR}$, RUNX2, ALP, and OCN (Fig. 7 F); and in vivo implantation indicating elevated bone formation capacity compared with the Ad-GFP-DKO-BMMSCs (Fig. $7 \mathrm{H}$ ). To avoid off-target effect, we used IL4R $\alpha$ neutralizing antibody to block IL4 signaling and found elevated expression of RUNX2 in DKO BMMSCs (Fig. 7 G). In contrast, Ad-Cre-DKO-BMMSCs showed a significant decrease in adipogenic differentiation compared with Ad-GFP-DKO-BMMSCs, as shown by a decreased number of Oil red O-positive cells and down-regulation of the adipogenic genes PPAR $\gamma 2$ and LPL (Fig. 7, I and J).

We next generated Prrx1-Cre;Mtor ${ }^{f /+} ; F_{b n} 1^{+/-}$TKO mice to $\mathrm{KO}$ mTOR in Fbn $1^{+/-}$BMMSCs (Fig. $8 \mathrm{~A}$ ). Mtor ${ }^{f /+}$ littermates were used as normal control, and $\mathrm{Mtor}^{f /+} ; \mathrm{Fbn}^{+/-}(\mathrm{DKO})$ littermates were used as osteopenia models (Fig. 8 A). The efficacy of Cre-medicated deletion of floxed allele was shown by qPCR analysis (Fig. 8 B). MicroCT analysis showed that Mtor conditional KO rescued BMD in Fbn1 deficiency-induced osteopenia (Fig. 8 C). Histological analysis showed that trabecular bone volume in TKO mice was increased compared with the DKO mice (Fig. 8 D). The numbers of adipocytes in TKO mouse BM were significantly reduced when compared with the DKO mice, as assessed by Oil red O staining (Fig. 8 D). To investigate the role of $\mathrm{mTOR}$ in the differentiation of Fbn1 deficient BMMSCs, we isolated BMMSCs from DKO mice and knocked down Mtor using an adenovirus expressing Cre with GFP or an adenovirus expressing GFP only as a control. Ad-Cre-DKO-BMMSCs showed significantly increased osteogenic differentiation, as assessed by alizarin red staining indicating elevated mineralized nodule formation (Fig. $8 \mathrm{E}$ ); Western blot analysis indicating rescued expression of the osteogenic cascade genes RUNX2, ALP, and OCN (Fig. 8 F); and in vivo implantation indicating elevated bone formation capacity compared with the Ad-GFP-DKO-BMMSCs (Fig. 8 G). In contrast, Ad-Cre-DKO-BMMSCs showed a significant decrease in adipogenic differentiation compared with Ad-GFPDKO-BMMSCs, as shown by a decreased number of Oil red $\mathrm{O}-$ positive cells and down-regulation of the adipogenic genes PPAR $\gamma 2$ and LPL (Fig. 8, $\mathrm{H}$ and I).

It has been shown that SP7-expressing osteoblastic progenitors have the ability to control osteoblastic/adipogenic lineage switch (Zhang et al., 2011; Song et al., 2012). To examine whether knocking down mTOR signaling in the preosteoblastic stage can recover the lineage alteration and osteopenia phenotype in $\mathrm{Fbn}^{+/-}$mice, we generated a tissue-specific $\mathrm{KO}$, SP7-Cre;Mtof ${ }^{f+} ; F_{b n} 1^{+/-}$(TKO) conditional Mtor KO mice (Fig. 9 A). Floxed Mtor littermates $\left(\right.$ Mtor $\left.^{f /+}\right)$ were used as normal control and $\mathrm{Mtor}^{f /+} ; \mathrm{Fbn} 1^{+/-}$(DKO) littermates were used as osteopenia models (Fig. 9 A). The efficacy of Cre-medicated deletion of floxed allele was shown by qPCR analysis (Fig. 9 B). MicroCT analysis and histological analyses showed that TKO mice have significantly increased BMD and trabecular bone volume compared with DKO mice (Fig. 9 C), suggesting that Mtor conditional KO in the preosteoblastic lineage rescued osteopenia in Fbn1-deficient mice. The number of adipocytes in TKO mouse BM was significantly reduced when compared with the DKO mice, as assessed by Oil red O staining (Fig. 9 C). These data prompted us to use a drug, specifically rapamycin, to attempt to ameliorate the disease phenotype in $\mathrm{Fbn}^{+/-}$mice.

Next, we examined whether rapamycin treatment rescued the osteopenia phenotype in $F b n 1^{+/-}$mice. Rapamycin was intraperitoneally administered to $F b n 1^{+/-}$mice at 8 or 6 wk of age for 14 or 28 consecutive days, respectively. The samples were harvested at $10 \mathrm{wk}$ of age for further evaluation (Fig. $10 \mathrm{~A}$ ). Histological and microCT analysis showed that rapamycin treatment elevated BMD and trabecular bone volume in Fbn $1^{+/-}$mice (Fig. 10 B). The number of adipocytes in BM of rapamycin-treated $\mathrm{Fbn} 1^{+/-}$mice was significantly reduced when compared with untreated $F b n 1^{+/-}$mouse BM, as assessed by Oil red $\mathrm{O}$ staining (Fig. $10 \mathrm{~B}$ ). BMMSCs isolated from 
rapamycin-treated $\mathrm{Fbn} 1^{+/-}$mice showed significantly increased CFU-F number compared with the untreated group (Fig. 10 C). Osteogenic differentiation of BMMSCs from rapamycin-treated Fbn $1^{+/-}$mice was markedly improved when compared with the untreated Fbn $1^{+/-}$BMMSCs, as analyzed by alizarin red staining to show elevated mineralized nodule formation and Western blot analysis to show decreased expression of $\mathrm{p}-\mathrm{mTOR}$ and p-P70S6K and increased expression of the RUNX2, ALP, and OCN (Fig. 10, D and E). In contrast, BMMSCs isolated from rapamycin-treated $\mathrm{Fbn} 1^{+/-}$mice showed a significant decrease in adipogenic differentiation compared with the untreated $\mathrm{Fbn}^{+/-}$BMMSCs, as shown by decreased number of Oil red O-positive cells and down-regulation of the PPAR $\gamma 2$ and LPL (Fig. 10, F and G).

\section{DISCUSSION}

FBN1 is essential for the formation of elastic fibers or microfibrils that provide strength and flexibility to connective tissue. Normally, FBN1 is abundant in the connective tissue of the aorta, ligature of the human eye lens, bones, and lungs.
Mutation of the fibrillin gene causes SSc and Marfan's syndrome, in which bone and connective tissue disorders are observed. The bone defects in SSc patients were considered to be an insignificant clinical symptom; however, recent emerging evidence shows that bone resorption may be a common clinical manifestation (Atteritano et al., 2013; Kilic et al., 2013; Omair et al., 2013). In the present study, we identified a marked osteopenia phenotype in Fbn1 mutant-induced SSc mice. Recently, it was suggested that FBN1 and FBN2 might differentially regulate endogenous BMP and TGF- $\beta$ activity in osteoblasts to affect bone growth and development (Nistala et al., 2010). In this study, we reveal that Fbn1 deficiency results in an increased level of TGF- $\beta$ in BM, which, in turn, initiates a cascade in which IL $4 \mathrm{R} \alpha$ is up-regulated in BMMSCs via SMAD3/SP1 binding to $I l 4 r \alpha$ promoter, leading, as a consequence, to the activation of mTOR-P70S6K signaling to directly suppress osteogenesis via RUNX2 and promote adipogenesis via $\operatorname{PPAR} \gamma 2$, respectively. Osteogenic differentiation deficiency in $\mathrm{Fbn} 1^{+/-}$ BMMSCs may contribute to an osteoporotic phenotype, such as low BMD or reduced trabecular bone structure, in $F b n 1^{+/-}$ $\mathrm{SSc}$ mice. However, inhibition of mTOR signaling using
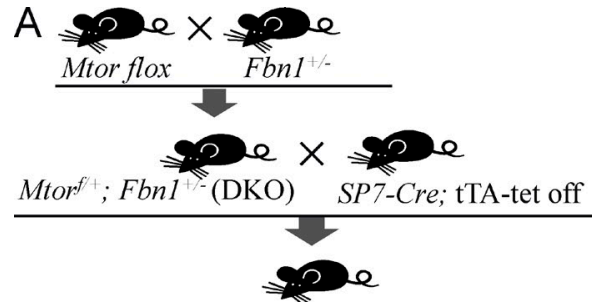

SP7-Cre; Mtorf ${ }^{+} ;$Fbn $^{+/-}(\mathrm{TKO})$
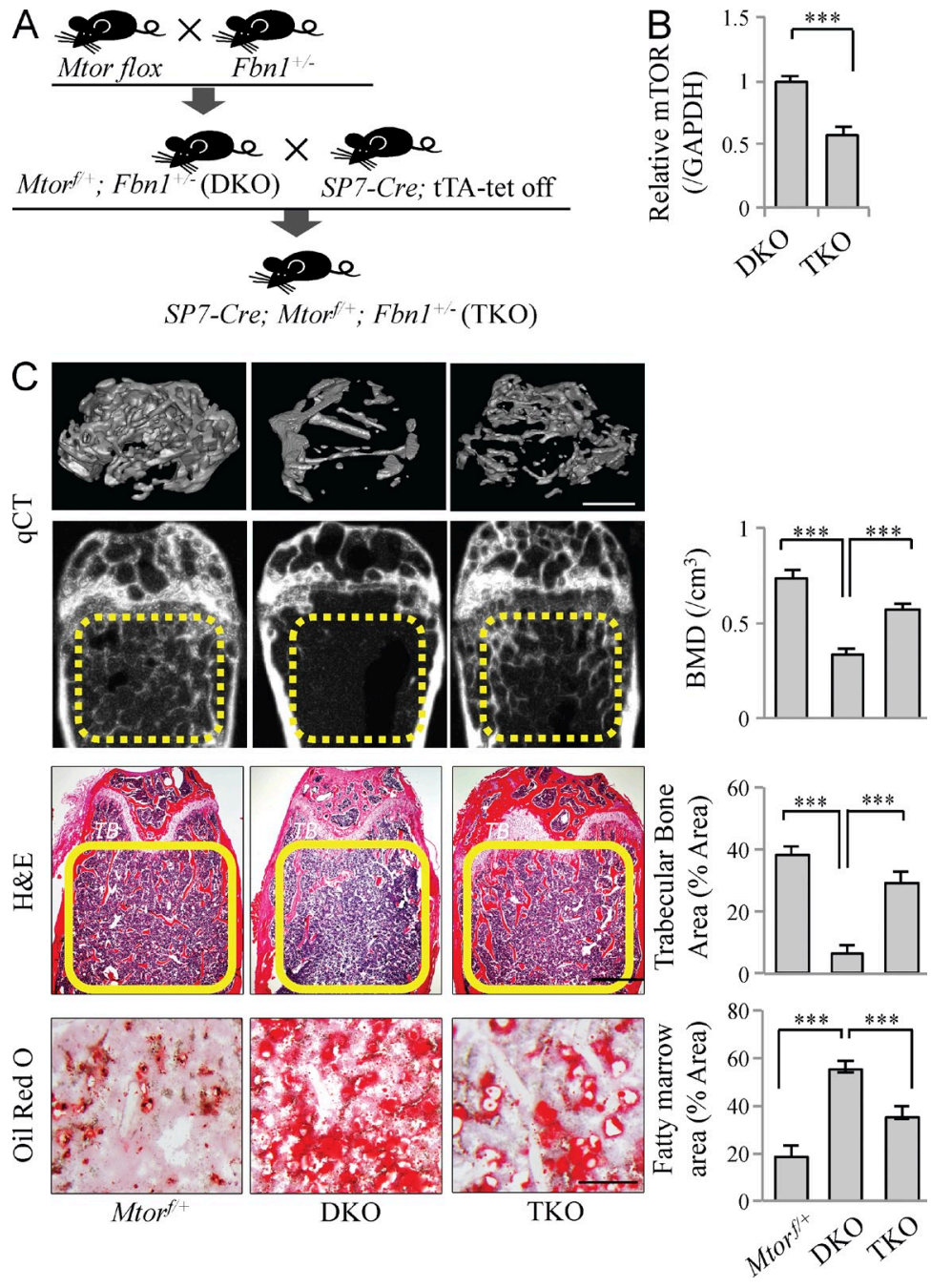

Figure 9. Conditional KO of mTOR in preosteoblastic lineage ameliorates osteopenia phenotype. (A) Experimental outline describing the generation of $\mathrm{Mtor}^{\mathrm{f} /+} ; \mathrm{Fbn} \mathrm{1}^{+/-}(\mathrm{DKO}, n=6)$ and Sp7-Cre;Mtorf/+;Fbn 1+/- (TKO, $n=6)$ mice. (B) qPCR analysis showed the efficacy of Cre-medicated deletion of the floxed allele. (C) MicroCT (bar, $1 \mathrm{~mm}), \mathrm{H} \& \mathrm{E}$ (bar, $1 \mathrm{~mm}$ ), and Oil red 0 (bar, $50 \mu \mathrm{m}$ ) staining showed BMD, TB volume, and the number of adipocytes in distal femur of DKO and TKO mice. All experimental data verified in at least three independent experiments. Error bars represent the SD from the mean values. ${ }^{* *}, \mathrm{P}<0.005$. 
A
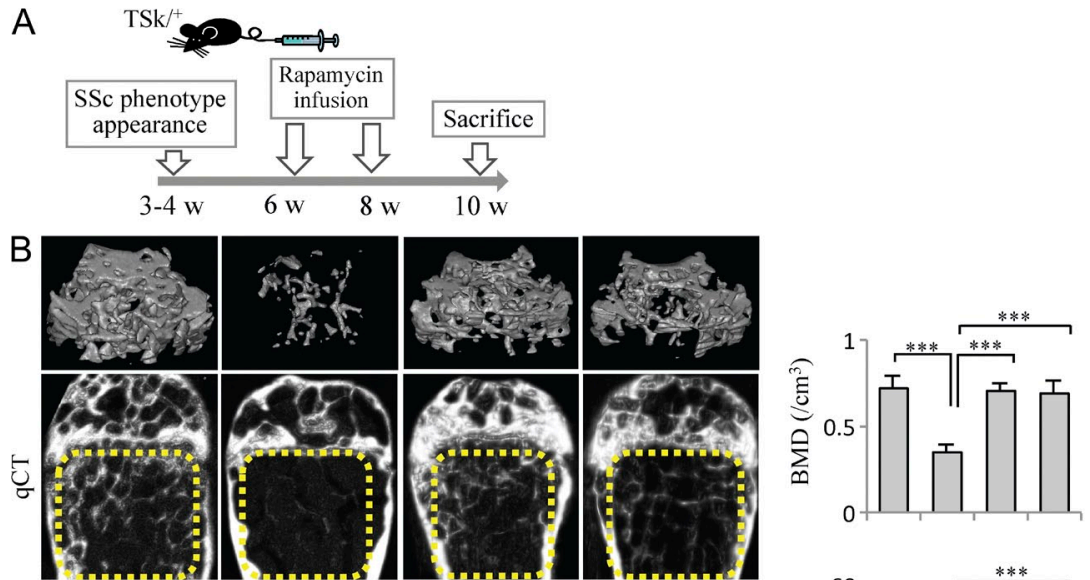
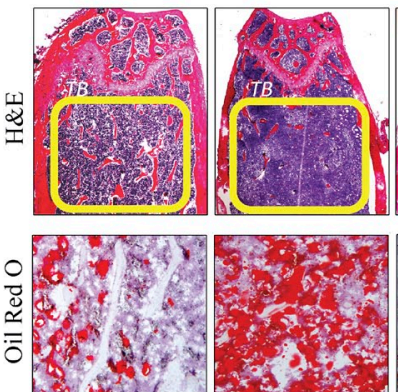

$\mathrm{Fbnl}^{+/}$
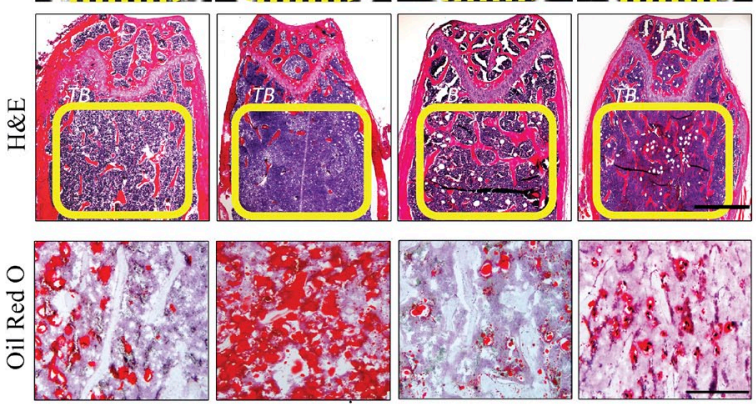

WT

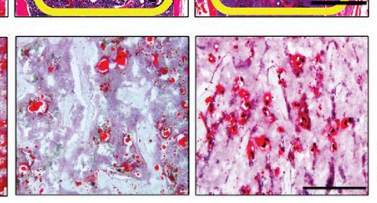

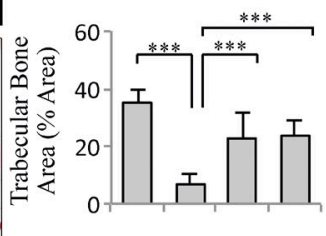

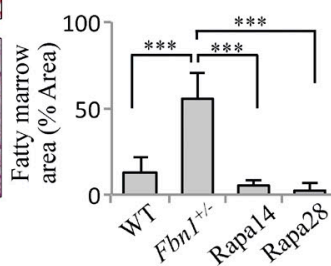

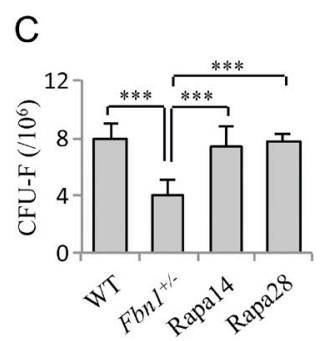

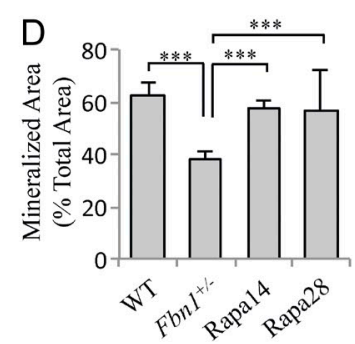

$\mathrm{F}$
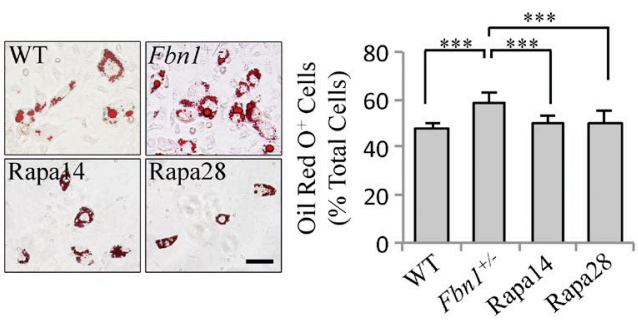

Figure 10. Rapamycin treatment ameliorates osteopenia phenotype by rescuing impaired osteogenic/adipogenic differentiation of BMMSCs in Fbn $1^{+/-}$mice. (A) Experimental outline describing the use of rapamycin to treat Fon $1^{+1-}$ mice $(n=6$ per group). (B) MicroCT, H\&E (bar, $1 \mathrm{~mm}$ ), and Oil red 0 (bar, $50 \mu \mathrm{m}$ ) staining showed BMD, TB volume, and adipocytes in distal femur of Fon ${ }^{1+-}$ mice after rapamycin treatment. (C) CFU-F number of BMMSCs isolated from rapa-treated Fbn 1+/- mice compared with Fbn 1+/- mice. (D) Alizarin red staining showed the mineralized nodule forming capacity in BMMSCs from rapa-treated Fon+l- mice. (E) Western blot showed the expression levels of $p$-mTOR, p-P70S6K, RUNX2, ALP, and OCN in BMMSCs from rapa-treated Fon 1+1- $^{+}$ mice. (F) Oil red 0 staining showed the number of adipocytes in rapa-treated Fon 1+/- BMMSCs. Bar, $50 \mu \mathrm{m}$. (G) Western blot showed the expression levels of PPAR 2 and LPL in rapa-treated Fon 1+- BMMSCs. All experimental data verified in at least three independent experiments. Error bars represent the SD from the mean values. ${ }^{* *}, P<0.005$. rapamycin treatment appears to be a promising approach to rescue osteoporotic disorders in the SSc mice.

It is known that mTOR signaling positively regulates expression of the adipogenic gene PPAR $\gamma 2$, which is critical for adipogenesis of BMMSCs (Kim and Chen, 2004; Yu et al., 2008; Zhang et al., 2009). However, controversial findings were reported regarding mTOR signaling in osteogenesis in that mTOR may be required for osteoblast proliferation, which is involved in several signaling pathways through IL6 (Kozawa et al., 2001; Takai et al., 2007; Takai et al., 2008). In contrast, rapamycin may either inhibit (Shoba and Lee, 2003) or stimulate
(Lee et al., 2010b; Martin et al., 2010) osteogenesis, depending on cell type or differentiation stages. Recently, it has been reported that bone matrix secretes IGF-1 (insulin-like growth factor-1) to recruit normal BMMSCs for bone remodeling by activating mTOR signaling (Xian et al., 2012), indicating that mTOR may contribute to the activation of different sets of biological regulatory controls under certain conditions. In this study, we reveal that elevated IL4R $\alpha$ expression leads to the activation of mTOR-P70S6K signaling in Fbn1 ${ }^{+/-}$BMMSCs, which directly inhibits the osteogenic gene RUNX2 and suppresses bone regeneration in vitro and in vivo. In contrast, rapamycin represses 
mTOR/P70S6K signaling, which results in rescuing BMMSC deficiency and ameliorating the osteoporotic phenotype in Fbn $1^{+/-}$mice, implicating that IL4R $\alpha / \mathrm{mTOR}$ is, in fact, a major signaling pathway contributing to the osteopenia phenotype in $\mathrm{Fbn}^{+/-}$mice. mTORC1 controls multiple cellular regulation processes, such as protein synthesis, cell proliferation, metabolism, and autophagy (Huang and Fingar, 2014). It is possible that activation of the mTORC1 pathway increases biosynthetic activity to improve osteogenesis rather than decrease bone formation. Thus, the mechanistic details may not totally explain the phenotype and further study is required to explore the detailed relationship between the mechanism and the phenotype. Because $F b n 1^{-/-}$mice are embryonic lethal, we cannot examine whether Fbn1 null shows a phenotype similar to that observed in Fbn1-deficient conditions.

$\mathrm{T}_{\mathrm{H}} 2$ cells are a major source of IL4 production in SSc (Kodera et al., 2002; Gabrielli et al., 2009). Fbn $1^{+/-}$mice show $\mathrm{T}_{\mathrm{H}} 2$ infiltration and high levels of IL4. Disruption of IL4 can rescue the fibrotic phenotype, suggesting that a high level of IL4 may also play a critical role in the disease pathogenesis (Kodera et al., 2002; Wynn, 2004; Gabrielli et al., 2009). Recent studies show that TGF- $\beta$ contributes to the fibrotic phenotype in SSc through activation of extracellular matrix protein expression, suggesting that TGF- $\beta$ and IL4 signaling may synergistically activate downstream targets to induce fibrosis in SSc (Varga and Abraham, 2007; Gabrielli et al., 2009; Gerber et al., 2013). Although overproduction of IL4 can induce osteoporotic phenotype in mice (Lewis et al., 1993), activation of IL4R $\alpha$ may inhibit osteoblast proliferation (Frost et al., 2001), indicating that IL4 may affect BMMSC function. Conversely, it was reported that local delivery of IL4, using a gene therapy approach, prevented bone erosion in arthritis animal models via abrogation of osteoclastogenesis (Lubberts et al., 2000; Woods et al., 2001; Saidenberg-Kermanac'h et al., 2004). These findings indicate that elevated IL4 caused by Fbn 1 deficiency may contribute to a low osteoblast/osteoclast turnover rate, as observed in $\mathrm{Fbn}^{+/-}$mice. It was reported that TGF- $\beta$ stimulates osteoclastogenesis via the TAK1-NF-кB pathway (Mizukami et al., 2002; Gingery et al., 2008). IL4 is a potent inhibitor of osteoclastogenesis that operates through various mechanisms, such as rapid suppression of NFATc1 expression (Wei et al., 2002; Cheng et al., 2011) and reduction of RANKL expression (Fujii et al., 2012) via activation of the STAT6 pathway. Our results showed that Prrx1-Cre-mediated knockdown of IL $4 \mathrm{R} \alpha$ rescued the osteopenia phenotype and altered BMMSC lineage differentiation in $\mathrm{Fbn}^{+/-}$mice; however, elevated serum TGF- $\beta$ levels were unchanged. Therefore, IL 4 signaling may play a critical role in determining osteoclastogenesis in $\mathrm{Fbn}^{+/-}$mice. Our data also suggest that IL4/IL $4 \mathrm{R} \alpha$ signaling activates mTOR signaling in Fbn $1^{+/-}$BMMSCs, which alters BMMSC osteogenic/adipogenic lineage differentiation, as a consequence of reduced osteogenesis and elevated adipogenesis in BM.

The lineage switch between osteoblasts and adipocytes may be regulated by multiple mechanisms, including at least IL4R/mTOR signaling at the early BMMSC (Prrx 1-Cre) and osteoblastic progenitor stages (SP7-Cre). Previous studies showed that SP7-expressing osteoblastic progenitors have the ability to control the osteoblastic/adipogenic lineage switch (Zhang et al., 2011; Song et al., 2012) and that SP7 can be regulated by small microRNA (Zhang et al., 2011). Our data showed that SP7-Cre-mediated KO of IL4R $\alpha / \mathrm{mTOR}$ cascades can rescue the BMMSC lineage alteration and osteopenia phenotype in $\mathrm{Fbn}^{+/-}$mice. These data may encourage us to use a drug such as rapamycin to ameliorate the disease phenotype in $F b n 1^{+/-}$mice. Rapamycin, a specific mTOR inhibitor, is a novel nonsteroidal anticancer and immunosuppressive drug (Abraham and Wiederrecht, 1996; Wang et al., 2003; Shaw et al., 2004). Several preclinical studies showed that rapamycin is effective in treating autoimmune diseases, such as systemic lupus erythematosus and rheumatoid arthritis (Yoon, 2009; Islander et al., 2011). These diseases are usually associated with bone disorders (Weinstein, 2010). Although efficacy of rapamycin treatment in SSc patients must be assessed in clinical studies, phase I clinical trials showed optimal safety for its use in treating scleroderma patients (Su et al., 2009). Added experimental evidence showed that rapamycin treatment resulted in a significant improvement of skin phenotype with regulation of immune index, such as reducing the levels of IL4 and IL17 in Fbn1 ${ }^{+/-}$mice (Yoshizaki et al., 2010). These data suggest that the underlying mechanism of rapamycin-mediated treatment may be associated with immunomodulation, leading to the down-regulation of $\mathrm{T}_{\mathrm{H}} 2$ cells (Lee et al., 2010a). Up-regulation of osteogenesis and down-regulation of adipogenesis in rapamycin-treated $\mathrm{Fbnn}^{+/-}$mice via inhibition of mTOR signaling in BMMSCs may help to rebuild functional osteoblasts to improve niche microenvironment for immune cells and rebuild homeostasis for the immune system. Because of the extensive functional roles of rapamycin in immune, anticancer, and osteoporosis therapies, it is necessary to explore detailed mechanisms by which rapamycin may target several signaling pathways simultaneously.

\section{MATERIALS AND METHODS}

Animals. Female C57BL/6J, B6.Cg-Fbn1 ${ }^{\text {Tsk } / J, ~ B 6 . C g-T g(P r r x 1-c r e) 1 C j t / J, ~}$ B6.Cg-Tg (Sp7-tTA, tetO-EGFP/cre)1Amc/J, and B6.129S4-Mtortm1.2koz /J mice were purchased from The Jackson Laboratory and maintained in C57BL/6J background in at least 10 backcrosses. Age-matched female littermates were used in all experiments. Female immunocompromised nude mice (Beige $n u / n u$ XIDIII) were purchased from Harlan. IL $4 \mathrm{R} \alpha$ null $\left(I l 4 r \alpha^{-/-}\right)$and floxed $\left(I l 4 r \alpha^{\varphi / \varphi}\right.$; Herbert et al., 2004) mice were gifts from F. Brombacher (University of Cape Town, Cape Town, South Africa). To generate tissue-specific Cre-mediated $\mathrm{KO}$ models, $\mathrm{Cre}-$, floxed-, and $\mathrm{Fbn} 1^{+/-}$mice were intercrossed, and age-matched female littermates were used as WT controls. All animal experiments were performed under the institutionally approved protocols for the use of animal research (University of Southern California protocol numbers 11141, 11953, and 11327).

MicroCT analysis. Femurs were harvested and analyzed by Inveon microCT system (Siemens AG). Cross-sectional volumetric BMD was measured at right femur mid-diaphysis with a density phantom. Using 3-dimensional images, a region of interest in secondary spongiosa was manually drawn near the endocortical surface, and BV/TV was assessed as a cancellous bone morphometric parameter. 
In vivo BMMSC implantation assay. Approximately $4.0 \times 10^{6} \mathrm{BMMSC}$ were mixed with HA/TCP ceramic powders ( $40 \mathrm{mg}$; Zimmer Inc.) and subcutaneously implanted into 8-wk-old immunocompromised mice (Gronthos et al., 2000). At $8 \mathrm{wk}$ after implantation, the transplants were harvested, fixed in $4 \%$ PFA, and decalcified with 5\% EDTA, pH 7.4, followed by paraffin embedding. The 6- $\mu \mathrm{m}$ paraffin sections were stained with H\&E chemical staining. Total BV/TV was quantified by ImageJ software (National Institutes of Health).

In vivo Oil red $\mathbf{O}$ staining. To assess the adipose tissue in trabecular areas, femurs were fixed in 4\% paraformaldehyde and decalcified with 5\% EDTA, $\mathrm{pH}$ 7.4, followed by cryosection. Sections were stained with Oil Red O, and positive areas were quantified under microscopy and shown as a percentage of total areas.

In vivo rapamycin treatment. Rapamycin (LC Laboratories) was in the vehicle containing $0.2 \%$ sodium carboxymethylcellulose (Sigma-Aldrich) and $0.25 \%$ polysorbate 80 (Sigma-Aldrich). Rapamycin with vehicle was intraperitoneally administered to Fbn1-deficient mice at a dose of $1.5 \mathrm{mg} / \mathrm{kg} / \mathrm{d}$ for 14 and 28 d, respectively (Blazar et al., 1994). The disease group and control mice were treated with vehicle only. Treatment was started at age 6 or $8 \mathrm{wk}$, and all groups of mice were healthy.

Histology. To assess trabecular bone and BM areas, femurs were fixed in $4 \%$ paraformaldehyde (Sigma-Aldrich) and then decalcified with 5\% EDTA, $\mathrm{pH} 7.4$, followed by paraffin embedding. Paraffin sections $(6 \mu \mathrm{m})$ were stained with hematoxylin and eosin (H\&E) and analyzed by ImageJ software. To perform immunohistochemistry staining, the paraffin-embedded sections were blocked with serum matched to secondary antibodies, incubated with the ALP or IL4 specific antibodies (1:400; Santa Cruz Biotechnology, Inc.) at $4^{\circ} \mathrm{C}$ for overnight, and then stained using VECTASTAIN UNIVERSAL elite ABC kit and ImmPACT VIP Peroxidase Substrate kit (Vector Laboratories) according to the manufacturer's instruction. To quantify osteoclast activity, mature osteoclasts were determined by TRAP-positive cells on the bone surface. Deparaffinized sections were refixed with a mixture of $50 \%$ ethanol and $50 \%$ acetone for $10 \mathrm{~min}$. TRAP staining solutions (1.6\% naphthol AS-BI phosphate in $N, N$-dimethylformamide, $0.14 \%$ fast red-violet LB diazonium salt, $0.097 \%$ tartaric acid, and $0.04 \% \mathrm{MgCl}_{2}$ in $0.2 \mathrm{M}$ sodium acetate buffer at $\mathrm{pH}$ 5.0) were freshly made. The sections were incubated in the solution for $10 \mathrm{~min}$ at $37^{\circ} \mathrm{C}$ under shield and counterstained with toluidine blue. All reagents for TRAP staining were purchased from SigmaAldrich. To label the mineralization fronts, the mice were given subcutaneous injections of calcein (15 mg/kg body weight; Sigma-Aldrich) in $2 \%$ sodium bicarbonate solution 10 and $3 \mathrm{~d}$ before sacrifice. Bone dynamic histomorphometric analyses for MAR, MS/BS, and BFR/BS were performed according to the standardized nomenclature for bone histomorphometry (Parfitt et al., 1987).

ELISA. Peripheral blood serum and cell culture medium were collected, and sRANKL, OPG, IL4, and TGF- $\beta$ protein levels were analyzed using mouse ELISA Ready-SET-GO kits (eBioscience), according to the manufacturer's instructions. CTX levels were analyzed with a mouse C-telopeptide of type I collagen ELISA kit (Novateinbio), according to the manufacturer's instructions. Human IL4 and TGF- $\beta$ protein levels were analyzed using ELISA Ready-SET-GO kits (eBioscience), according to the manufacturer's instructions. Human sRANKL protein levels were analyzed using sRANKL Super X ELISA kit (Antigenix America Inc.) and OPG levels were analyzed by OPG instant ELISA kit (eBioscience), according to the manufacturer's instructions. For measurement of anti-dsDNA antibodies and ANA, peripheral blood serum samples were collected from all experimental mice and analyzed by commercially available ELISA kits (Alpha Diagnostics) according to the manufacturer's instructions.

Isolation of mouse BMMSCs. Single suspension of BM-derived all-nuclear cells $\left(\right.$ ANCs; $15 \times 10^{6}$ ) from femurs and tibias was seeded into $100 \mathrm{~mm}$ culture dishes (Corning) and cultured at $37^{\circ} \mathrm{C}$ with $5 \% \mathrm{CO}_{2}$. After $2 \mathrm{~d}$, nonadherent cells were removed, and attached cells were cultured for $16 \mathrm{~d}$ in $\alpha$-MEM (Invitrogen) supplemented with 20\% FBS, $2 \mathrm{mM}$ L-glutamine (Invitrogen), $55 \mu \mathrm{M} 2$-mercaptoethanol (Invitrogen), $100 \mathrm{U} / \mathrm{ml}$ penicillin, and $100 \mu \mathrm{g} / \mathrm{ml}$ streptomycin (Invitrogen). These plastic attached single colonies were passaged with frequent medium changes to eliminate potential hematopoietic cells contamination (Soleimani and Nadri, 2009; Zhu et al., 2010). Flow cytometric analysis was performed to show a surface epitope profile of isolated BMMSCs (Fig. 2 A). To further confirm that the single colony-derived plastic adherent BMMSCs were not contaminated with hematopoietic cells, we depleted $\mathrm{T}$ cells in BMMSC culture using $\mathrm{CD} 3$ antibody treatment. In brief, $1 \mathrm{ml} \mathrm{CD} 3$ antibody was added to $10^{7}$ BMMSCs and the mixture was incubated at $4^{\circ} \mathrm{C}$ for $30 \mathrm{~min}$. The cells were centrifuged for $5 \mathrm{~min}$ to remove unbound antibody, resuspended in $1 \mathrm{ml}$ diluted (1:6) rabbit complement (PelFreez Biologicals) and incubated at $37^{\circ} \mathrm{C}$ for $30 \mathrm{~min}$. Subsequently, CD3 antibody/complement treatment was repeated once (Gilmore et al., 1986). In addition, we sorted BMMSCs from BM cells according to their MSC-specific surface markers using flow cytometry, as reported previously (Houlihan et al., 2012). BM cells were selected by lineage markers $\left(\operatorname{Lin}^{-}\right)$and then sorted by PDGFR $\alpha$ and Sca-1 $(\mathrm{P} \alpha \mathrm{S})$. Alizarin Red staining and Western blot analysis showed that BMMSCs derived from plastic collected single colonies, CD3 antibody/complement depletion, and flow cytometric sorting had similar osteogenic abilities (Fig. 2, B and C). For CFU-F assay, $10^{6}$ ANCs from BM were seeded in T25 cell culture flasks (Corning). After $16 \mathrm{~d}$, the cultures were washed by PBS and stained with $1 \%$ toluidine blue solution with $2 \%$ paraformaldehyde. The cell clusters with more than 50 cells were counted as colonies under microscopy.

Osteogenic differentiation assay. BMMSCs were cultured under osteogenic culture condition, containing $2 \mathrm{mM} \beta$-glycerophosphate (Sigma-Aldrich), $100 \mu \mathrm{M}$ L-ascorbic acid 2-phosphate (Wako), and $10 \mathrm{nM}$ dexamethasone (Sigma-Aldrich) in the growth medium. After 3 wk induction, 1\% Alizarin Red S (Sigma-Aldrich) staining was performed to detect matrix mineralization, and the stained areas were quantified by ImageJ software and shown as a percentage of the total area.

Western immunoblotting. Cells were lysed in M-PER mammalian protein extraction reagent (Thermo Fisher Scientific) with protease and phosphatase inhibitors (Roche), and proteins were quantified using protein concentration assay (Bio-Rad Laboratories). $20 \mu \mathrm{g}$ of proteins were separated by SDSPAGE and transferred to $0.2 \mu \mathrm{m}$ nitrocellulose membranes (Millipore). The membranes were blocked with 5\% nonfat dry milk and $0.1 \%$ Tween-20 for $1 \mathrm{~h}$, followed by incubation overnight with the primary antibodies diluted in blocking solution according to manufacturer's instructions. Antibodies to mouse ALP, LPL, PPAR $\gamma 2$, IL4R $\alpha$, PI3K-p110, phosphor-SMAD2/3, and SP1 were purchased from Santa Cruz Biotechnology, Inc. Antibodies to human RUNX2, ALP, and OCN were purchased from Santa Cruz Biotechnology, Inc. Antibodies to phosphor-mTOR (Ser2448), mTOR, phospho-Akt (Ser473), Akt, phosphor-P70S6K (T389; S371), phosphor-Rictor, phosphorRaptor, and SMAD2/3 were obtained from Cell Signaling Technology. Antibodies to mouse RUNX2, FBN1, OCN, and $\beta$-actin were purchased from Abcam, GeneTex, Millipore, and Sigma-Aldrich. The membranes were then incubated for $1 \mathrm{~h}$ in HRP-conjugated secondary antibody (Santa Cruz Biotechnology, Inc.) diluted at 1:10,000 in blocking solution. Immunoreactive proteins were detected using SuperSignal West Pico Chemiluminescent Substrate (Thermo Fisher Scientific) and BioMax film (Kodak). The intensity of bands was measured by using ImageJ software and normalized to $\beta$-actin.

Adipogenic differentiation. For adipogenic induction, $500 \mathrm{nM}$ isobutylmethylxanthine (Sigma-Aldrich), $60 \mu \mathrm{M}$ indomethacin (Sigma-Aldrich), $500 \mathrm{nM}$ hydrocortisone (Sigma-Aldrich), $10 \mu \mathrm{g} / \mathrm{ml}$ insulin (Sigma-Aldrich), and $100 \mathrm{nM} \mathrm{L-ascorbic} \mathrm{acid} \mathrm{phosphate} \mathrm{were} \mathrm{added} \mathrm{into} \mathrm{the} \mathrm{growth} \mathrm{medium.}$ After $7 \mathrm{~d}$, the cultured cells were stained with Oil red O (Sigma-Aldrich), and positive cells were quantified under microscopy and shown as a number to total cells. 
RNAi and chemical reagent treatments. BMMSCs $\left(0.5 \times 10^{6}\right)$ were seeded to a 6-well culture plate and treated with Fbn1 siRNA (Santa Cruz Biotechnology, Inc.), P70s6k siRNA (Santa Cruz Biotechnology, Inc.), Il $4 r \alpha$ shRNA (Santa Cruz Biotechnology, Inc.), or Mtor shRNA (Addgene), according to the manufacturers' instructions. After transfection, cells were either used for protein extraction for Western immunoblotting or for differentiation induction. For chemical reagent treatments, serum-starved MSCs were treated with 10-100 ng/ml rIL-4 (R\&D Systems), $50 \mathrm{nM}$ rapamycin (LC Laboratories), or $1 \mu \mathrm{g} / \mathrm{ml}$ TGF- $\beta$ neutralized antibody (R\&D Systems). For Western immunoblotting, MSCs were cultured under growth medium with drugs for $24 \mathrm{~h}$, and protein was extracted by using M-PER mammalian protein extraction reagent. For differentiation induction, MSCs were cultured under inductive conditions in the presence of drugs (added every $3 \mathrm{~d}$ ) for $3 \mathrm{wk}$, followed by staining and gene expression analysis.

Flow cytometric analysis of $\mathbf{T}_{\mathrm{H}} \mathbf{2}$ cells. To detect $\mathrm{T}_{\mathrm{H}} 2$ percentage of $\mathrm{CD} 4^{+}$ cells in BM and splenocyte (Ansel et al., 2004), BM or splenocyte-derived single-suspension ANCs were incubated with anti-CD4-PerCP (BioLegend), followed by staining with anti-IFN- $\boldsymbol{\gamma}$-APC (BioLegend) and anti-IL4-PE (eBioscience), anti-IL5-PE (eBioscience), or anti-IL13-eFluor 660 (eBioscience) using an intracellular antigen staining kit (eBioscience). To further identify $\mathrm{T}_{\mathrm{H}} 2$ cells infiltration, ANCs were incubated with anti-CD4-PerCP, followed by staining with combined $\mathrm{T}_{\mathrm{H}} 2$ cytokines, such as anti-IL4-PE/antiIL13-eFluor 660 and anti-IL5-PE/anti-IL13-eFluor 660 antibodies, using an intracellular antigen staining kit. Because CC-chemokine receptor 3 (CCR3) has been reported as a marker for $\mathrm{T}_{\mathrm{H}} 2$ cells (Sallusto et al., 1997), we detected $\mathrm{CD} 4^{+} \mathrm{CCR}^{+}, \mathrm{CD}^{+}{ }^{+} \mathrm{CCR} 3^{+} \mathrm{IL}^{+}$, and $\mathrm{CD} 4^{+} \mathrm{CCR} 3^{+} \mathrm{IL} 13^{+}$subpopulations using anti-CCR3-FITC antibody (BioLegend). Cells were analyzed by FACS Calibur with CellQuest software (BD).

Immunofluorescent microscopy. BMMSCs were cultured on 4-well chamber slides (Nunc; $2 \times 10^{3} /$ well) and then fixed with $4 \%$ paraformaldehyde. The Chamber slides are incubated with primary anti CD73 antibody $(1: 400 ; \mathrm{BD})$ and anti-IL4R $\alpha(1: 400 ; \mathrm{BD})$ at $4^{\circ} \mathrm{C}$ for overnight and then treated with Rhodamine-conjugated secondary antibody (1:400; SouthernBiotech) or Alexa Fluor 488-conjugated secondary antibody (1:200, Invitrogen) for $30 \mathrm{~min}$ at room temperature. Finally, slides were mounted with VECTASHIELD mounting medium (Vector Laboratories).

IL4-treated in vivo BMMSC implantation assay. BMMSCs were mixed with HA/TCP ceramic powders, and Extracel-HP hydrogel (Glycosan Biosystems), containing $200 \mathrm{ng}$ IL4, was covered on the surface of the implants for slow release of the cytokine (Liu et al., 2011). At $8 \mathrm{wk}$ after implantation, the implants were harvested and decalcified. Newly formed mineralized tissue areas were analyzed by paraffin section and H\&E staining.

Luciferase reporter assay. Promoter reporters were prepared as our previous description (Chen et al., 2014). Il $4 r \alpha$-luciferase promoter reporter constructs were generated by PCR using Pfu polymerase and mouse genomic DNA as a template. Primers containing upstream XhoI and HindIII downstream restriction sites were used to generate $I / 4 r \alpha$ promoter fragment (forward, 5'-CTCGAGGAATTCATGCTGCTTTCTCG-3' , and reverse, 5'-AAGCTTGGCTTTCCCACCGCCCGTT-3'). Restriction-digested PCR products were subcloned into pGL3-Basic vector (Promega). Point mutants were introduced into the reporter by the Pfu-DpnI method. All clones were confirmed by sequencing on both strands. BMMSCs cultured in 6-well plates were cotransfected with $2 \mu \mathrm{g}$ of luciferase reporter and $100 \mathrm{ng}$ Renilla luciferase expression vector to control for transfection efficiency. $48 \mathrm{~h}$ after transfection, cells were lysed in $1 \times$ passive lysis buffer, and luciferase activity was measured using the Dual-Glo Luciferase System (Promega) and a luminometer (Turner Biosystems).

ChIP assays. BMMSCs grown in 10-cm cell culture dishes were fixed for $10 \mathrm{~min}$ at room temperature by addition of $1 \%$ paraformaldehyde to the growth medium. Cells were washed twice in cold PBS supplemented with complete protease inhibitor cocktail and gently scraped from the plate. Cell lysis and ChIP were performed using the ChIP Assay kit (Millipore). For chromatin fragmentation, cells were sonicated using a Branson Sonifier 450 on power setting 4 in 30-s bursts with 1 min cooling on ice for a total sonication time of $4 \mathrm{~min}$. For immunoprecipitations, 1:100 dilution of SP1 antibody was used to capture protein-DNA complexes, and isotype-matched IgG was used as negative control. All resulting precipitated DNA samples were quantified with real-time PCR and expressed as the percentage of input DNA.

Statistics. All experimental group sizes were chosen to ensure adequate statistical power despite the highly variable nature of the studies performed. No animal excluded, and animals were randomly assigned groups for the studies. All experiments were not performed in a blinded fashion. Data were assessed for normal distribution and similar variance between groups. Comparisons between two groups were analyzed by independent unpaired two-tailed Student's $t$ test, and the comparisons between more than two groups were analyzed by one-way ANOVA with the Bonferroni adjustment. The p-values $<0.05$ were considered statistically significant.

We thank Dr. Xiaohong Duan and Mr. Tao Zhou from the Fourth Military Medical University for generating the microCT images.

This work was supported by grants from the National Institute of Dental and Craniofacial Research, National Institutes of Health, Department of Health and Human Services (R01DE017449 and R01DE019932 to S. Shi), and a grant from the California Institute for Regenerative Medicine (RN1-00572 for S. Shi).

The authors declare no competing financial interests.

Submitted: 6 April 2014

Accepted: 5 December 2014

\section{REFERENCES}

Abraham, R.T., and G.J. Wiederrecht. 1996. Immunopharmacology of rapamycin. Annu. Rev. Immunol. 14:483-510. http://dx.doi.org/10.1146/ annurev.immunol.14.1.483

Akiyama, K., C. Chen, D. Wang, X. Xu, C. Qu, T. Yamaza, T. Cai, W. Chen, L. Sun, and S. Shi. 2012. Mesenchymal-stem-cell-induced immunoregulation involves FAS-ligand-/FAS-mediated T cell apoptosis. Cell Stem Cell. 10:544-555. http://dx.doi.org/10.1016/j.stem.2012.03.007

Ansel, K.M., R.J. Greenwald, S. Agarwal, C.H. Bassing, S. Monticelli, J. Interlandi, I.M. Djuretic, D.U. Lee, A.H. Sharpe, F.W. Alt, and A. Rao. 2004. Deletion of a conserved Il4 silencer impairs T helper type 1-mediated immunity. Nat. Immunol. 5:1251-1259. http://dx.doi.org/ 10.1038/ni1135

Atteritano, M., S. Sorbara, G. Bagnato, G. Miceli, D. Sangari, S. Morgante, E. Visalli, and G. Bagnato. 2013. Bone mineral density, bone turnover markers and fractures in patients with systemic sclerosis: a case control study. PLoS ONE. 8:e66991. http://dx.doi.org/10.1371/journal.pone.0066991

Barisic-Dujmovic, T., I. Boban, D.J. Adams, and S.H. Clark. 2007. Marfanlike skeletal phenotype in the tight skin (Tsk) mouse. Calcif. Tissue Int 81:305-315. http://dx.doi.org/10.1007/s00223-007-9059-4

Blazar, B.R., P.A. Taylor, S.N. Sehgal, and D.A. Vallera. 1994. Rapamycin, a potent inhibitor of $\mathrm{T}$-cell function, prevents graft rejection in murine recipients of allogeneic T-cell-depleted donor marrow. Blood. 83:600-609.

Charbonneau, N.L., R.N. Ono, G.M. Corson, D.R. Keene, and L.Y. Sakai 2004. Fine tuning of growth factor signals depends on fibrillin microfibril networks. Birth Defects Res. C Embryo Today. 72:37-50. http://dx .doi.org/10.1002/bdrc. 20000

Chen, C., K. Akiyama, T. Yamaza, Y.O. You, X. Xu, B. Li, Y. Zhao, and S. Shi. 2014. Telomerase governs immunomodulatory properties of mesenchymal stem cells by regulating FAS ligand expression. EMBO Mol. Med. 6: 322-334

Cheng, J., J. Liu, Z. Shi, D. Xu, S. Luo, G.P. Siegal, X. Feng, and S. Wei. 2011. Interleukin-4 inhibits RANKL-induced NFATc1 expression via STAT6: a novel mechanism mediating its blockade of osteoclastogenesis. J. Cell. Biochem. 112:3385-3392. http://dx.doi.org/10.1002/jcb.23269

Dietz, H.C., G.R. Cutting, R.E. Pyeritz, C.L. Maslen, L.Y. Sakai, G.M. Corson, E.G. Puffenberger, A. Hamosh, E.J. Nanthakumar, S.M. 
Curristin, et al. 1991. Marfan syndrome caused by a recurrent de novo missense mutation in the fibrillin gene. Nature. 352:337-339. http:// dx.doi.org/10.1038/352337a0

Dietz, H.C., F. Ramirez, and L.Y. Sakai. 1994. Marfan's syndrome and other microfibrillar diseases. Adv. Hum. Genet. 22:153-186. http://dx.doi.org/ 10.1007/978-1-4757-9062-7_4

Dietz, H.C., B. Loeys, L. Carta, and F. Ramirez. 2005. Recent progress towards a molecular understanding of Marfan syndrome. Am. J. Med. Genet. C. Semin. Med. Genet. 139C:4-9. http://dx.doi.org/10.1002/ajmg.c.30068

Docagne, F., C. Gabriel, N. Lebeurrier, S. Lesné, Y. Hommet, L. Plawinski, E.T. Mackenzie, and D. Vivien. 2004. Sp1 and Smad transcription factors co-operate to mediate TGF- $\beta$-dependent activation of amyloid-beta precursor protein gene transcription. Biochem. J. 383:393-399. http:// dx.doi.org/10.1042/BJ20040682

Friedenstein, A.J., R.K. Chailakhyan, N.V. Latsinik, A.F. Panasyuk, and I.V. Keiliss-Borok. 1974. Stromal cells responsible for transferring the microenvironment of the hemopoietic tissues. Cloning in vitro and retransplantation in vivo. Transplantation. 17:331-340. http://dx.doi.org/ 10.1097/00007890-197404000-00001

Frost, A., K.B. Jonsson, H. Brändström, S. Ljunghall, O. Nilsson, and O. Ljunggren. 2001. Interleukin (IL)-13 and IL-4 inhibit proliferation and stimulate IL-6 formation in human osteoblasts: evidence for involvement of receptor subunits IL-13R, IL-13R $\alpha$, and IL-4R $\alpha$. Bone. 28:268-274. http://dx.doi.org/10.1016/S8756-3282(00)00449-X

Fujii, T., H. Kitaura, K. Kimura, Z.W. Hakami, and T. Takano-Yamamoto. 2012. IL-4 inhibits TNF- $\alpha$-mediated osteoclast formation by inhibition of RANKL expression in TNF- $\alpha$-activated stromal cells and direct inhibition of TNF- $\alpha$-activated osteoclast precursors via a T-cell-independent mechanism in vivo. Bone. 51:771-780. http://dx.doi.org/10.1016/j.bone .2012.06.024

Gabrielli, A., E.V. Avvedimento, and T. Krieg. 2009. Scleroderma. N. Engl. J. Med. 360:1989-2003. http://dx.doi.org/10.1056/NEJMra0806188

Gerber, E.E., E.M. Gallo, S.C. Fontana, E.C. Davis, F.M. Wigley, D.L. Huso, and H.C. Dietz. 2013. Integrin-modulating therapy prevents fibrosis and autoimmunity in mouse models of scleroderma. Nature. 503:126-130. http://dx.doi.org/10.1038/nature12614

Gilmore, M.J., J. Patterson, K. Ivory, M.K. Brenner, S. Graphakos, G. Janossy, A.V. Hoffbrand, and H.G. Prentice. 1986. Standardization of T-cell depletion in HLA matched bone marrow transplantation. Br. J. Haematol. 64:69-75. http://dx.doi.org/10.1111/j.1365-2141.1986.tb07574.x

Gingery, A., E.W. Bradley, L. Pederson, M. Ruan, N.J. Horwood, and M.J. Oursler. 2008. TGF- $\beta$ coordinately activates TAK1/MEK/ AKT/NFKB and SMAD pathways to promote osteoclast survival. Exp. Cell Res. 314:2725-2738. http://dx.doi.org/10.1016/j.yexcr .2008 .06 .006

Gronthos, S., M. Mankani, J. Brahim, P.G. Robey, and S. Shi. 2000. Postnatal human dental pulp stem cells (DPSCs) in vitro and in vivo. Proc. Natl. Acad. Sci. USA. 97:13625-13630. http://dx.doi.org/10.1073/ pnas. 240309797

Herbert, D.R., C. Hölscher, M. Mohrs, B. Arendse, A. Schwegmann, M. Radwanska, M. Leeto, R. Kirsch, P. Hall, H. Mossmann, et al. 2004. Alternative macrophage activation is essential for survival during schistosomiasis and downmodulates $\mathrm{T}$ helper 1 responses and immunopathology. Immunity. 20:623-635. http://dx.doi.org/10.1016/S10747613(04)00107-4

Holm, T.M., J.P. Habashi, J.J. Doyle, D. Bedja, Y. Chen, C. van Erp, M.E. Lindsay, D. Kim, F. Schoenhoff, R.D. Cohn, et al. 2011. Noncanonical TGF $\beta$ signaling contributes to aortic aneurysm progression in Marfan syndrome mice. Science. 332:358-361. http://dx.doi.org/10 $.1126 /$ science. 1192149

Houlihan, D.D., Y. Mabuchi, S. Morikawa, K. Niibe, D. Araki, S. Suzuki, H. Okano, and Y. Matsuzaki. 2012. Isolation of mouse mesenchymal stem cells on the basis of expression of Sca- 1 and PDGFR- $\alpha$. Nat. Protoc. 7:2103-2111. http://dx.doi.org/10.1038/nprot.2012.125

Huang, K., and D.C. Fingar. 2014. Growing knowledge of the mTOR signaling network. Semin. Cell Dev. Biol. 36:79-90. http://dx.doi.org/10 .1016/j.semcdb.2014.09.011

Islander, U., C. Jochems, M.K. Lagerquist, H. Forsblad-d'Elia, and H. Carlsten. 2011. Estrogens in rheumatoid arthritis; the immune system and bone.
Mol. Cell. Endocrinol. 335:14-29. http://dx.doi.org/10.1016/j.mce.2010 .05 .018

Judge, D.P., N.J. Biery, D.R. Keene, J. Geubtner, L. Myers, D.L. Huso, L.Y. Sakai, and H.C. Dietz. 2004. Evidence for a critical contribution of haploinsufficiency in the complex pathogenesis of Marfan syndrome. J. Clin. Invest. 114:172-181. http://dx.doi.org/10.1172/ JCI200420641

Jungert, K., A. Buck, M. Buchholz, M. Wagner, G. Adler, T.M. Gress, and V. Ellenrieder. 2006. Smad-Sp1 complexes mediate TGF $\beta$-induced early transcription of oncogenic Smad7 in pancreatic cancer cells. Carcinogenesis. 27:2392-2401. http://dx.doi.org/10.1093/carcin/bgl078

Kilic, G., E. Kilic, O. Akgul, and S. Ozgocmen. 2013. Increased risk for bone loss in women with systemic sclerosis: a comparative study with rheumatoid arthritis. Int J Rheum Dis. In press.

Kim, J.E., and J. Chen. 2004. regulation of peroxisome proliferator-activated receptor- $\gamma$ activity by mammalian target of rapamycin and amino acids in adipogenesis. Diabetes. 53:2748-2756. http://dx.doi.org/10.2337/ diabetes.53.11.2748

Kodera, T., T.L. McGaha, R. Phelps, W.E. Paul, and C.A. Bona. 2002. Disrupting the IL-4 gene rescues mice homozygous for the tight-skin mutation from embryonic death and diminishes TGF- $\beta$ production by fibroblasts. Proc. Natl. Acad. Sci. USA. 99:3800-3805. http://dx.doi.org/ 10.1073/pnas.052709999

Kozawa, O., H. Matsuno, and T. Uematsu. 2001. Involvement of p70 S6 kinase in bone morphogenetic protein signaling: vascular endothelial growth factor synthesis by bone morphogenetic protein-4 in osteoblasts. J. Cell. Biochem. 81:430-436. http://dx.doi.org/10.1002/10974644(20010601)81:3<430::AID-JCB1056>3.0.CO;2-G

Le Blanc, K., I. Rasmusson, B. Sundberg, C. Götherström, M. Hassan, M. Uzunel, and O. Ringdén. 2004. Treatment of severe acute graft-versushost disease with third party haploidentical mesenchymal stem cells. Lancet. 363:1439-1441. http://dx.doi.org/10.1016/S0140-6736(04)16104-7

Lee, B., M. Godfrey, E. Vitale, H. Hori, M.G. Mattei, M. Sarfarazi, P. Tsipouras, F. Ramirez, and D.W. Hollister. 1991. Linkage of Marfan syndrome and a phenotypically related disorder to two different fibrillin genes. Nature. 352:330-334. http://dx.doi.org/10.1038/352330a0

Lee, K., P. Gudapati, S. Dragovic, C. Spencer, S. Joyce, N. Killeen, M.A. Magnuson, and M. Boothby. 2010a. Mammalian target of rapamycin protein complex 2 regulates differentiation of Th1 and Th2 cell subsets via distinct signaling pathways. Immunity. 32:743-753. http://dx.doi .org/10.1016/j.immuni.2010.06.002

Lee, K.W., J.Y. Yook, M.Y. Son, M.J. Kim, D.B. Koo, Y.M. Han, and Y.S. Cho. 2010b. Rapamycin promotes the osteoblastic differentiation of human embryonic stem cells by blocking the mTOR pathway and stimulating the BMP/Smad pathway. Stem Cells Dev. 19:557-568. http://dx.doi.org/10.1089/scd.2009.0147

Lemaire, R., J. Bayle, and R. Lafyatis. 2006. Fibrillin in Marfan syndrome and tight skin mice provides new insights into transforming growth factorbeta regulation and systemic sclerosis. Curr. Opin. Rheumatol. 18:582587. http://dx.doi.org/10.1097/01.bor.0000245719.64393.57

Lewis, D.B., H.D. Liggitt, E.L. Effmann, S.T. Motley, S.L. Teitelbaum, K.J. Jepsen, S.A. Goldstein, J. Bonadio, J. Carpenter, and R.M. Perlmutter. 1993. Osteoporosis induced in mice by overproduction of interleukin 4. Proc. Natl. Acad. Sci. USA. 90:11618-11622. http://dx.doi.org/10.1073/pnas .90 .24 .11618

Liu, Y., L. Wang, T. Kikuiri, K. Akiyama, C. Chen, X. Xu, R. Yang, W. Chen, S. Wang, and S. Shi. 2011. Mesenchymal stem cell-based tissue regeneration is governed by recipient T lymphocytes via IFN- $\boldsymbol{\gamma}$ and TNF- $\alpha$. Nat. Med. 17:1594-1601. http://dx.doi.org/10.1038/nm.2542

Lubberts, E., L.A. Joosten, M. Chabaud, L. van Den Bersselaar, B. Oppers, C.J. Coenen-De Roo, C.D. Richards, P. Miossec, and W.B. van Den Berg. 2000. IL-4 gene therapy for collagen arthritis suppresses synovial IL-17 and osteoprotegerin ligand and prevents bone erosion. J. Clin. Invest. 105:1697-1710. http://dx.doi.org/10.1172/JCI7739

Martin, S.K., S. Fitter, L.F. Bong, J.J. Drew, S. Gronthos, P.R. Shepherd, and A.C. Zannettino. 2010. NVP-BEZ235, a dual pan class I PI3 kinase and $\mathrm{mTOR}$ inhibitor, promotes osteogenic differentiation in human mesenchymal stromal cells. J. Bone Miner. Res. 25:2126-2137. http:// dx.doi.org/10.1002/jbmr.114 
Mizukami, J., G. Takaesu, H. Akatsuka, H. Sakurai, J. Ninomiya-Tsuji, K. Matsumoto, and N. Sakurai. 2002. Receptor activator of NF-кB ligand (RANKL) activates TAK1 mitogen-activated protein kinase kinase kinase through a signaling complex containing RANK, TAB2, and TRAF6. Mol. Cell. Biol. 22:992-1000. http://dx.doi.org/10.1128/MCB .22.4.992-1000.2002

Nistala, H., S. Lee-Arteaga, S. Smaldone, G. Siciliano, L. Carta, R.N. Ono, G. Sengle, E. Arteaga-Solis, R. Levasseur, P. Ducy, et al. 2010. Fibrillin- -1 and -2 differentially modulate endogenous TGF- $\beta$ and BMP bioavailability during bone formation. J. Cell Biol. 190:1107-1121. http://dx.doi.org/10.1083/jcb.201003089

Omair, M.A., C. Pagnoux, H. McDonald-Blumer, and S.R. Johnson. 2013 Low bone density in systemic sclerosis. A systematic review. J. Rheumatol. 40:1881-1890. http://dx.doi.org/10.3899/jrheum.130032

Parfitt, A.M., M.K. Drezner, F.H. Glorieux, J.A. Kanis, H. Malluche, P.J. Meunier, S.M. Ott, and R.R. Recker. Report of the ASBMR Histomorphometry Nomenclature Committee. 1987. Bone histomorphometry: standardization of nomenclature, symbols, and units. J. Bone Miner. Res. 2:595-610. http://dx.doi.org/10.1002/jbmr.5650020617

Prockop, D.J. 1997. Marrow stromal cells as stem cells for nonhematopoietic tissues. Science. 276:71-74. http://dx.doi.org/10.1126/science.276 .5309 .71

Quarto, N., B. Leonard, S. Li, M. Marchand, E. Anderson, B. Behr, U. Francke, R. Reijo-Pera, E. Chiao, and M.T. Longaker. 2012. Skeletogenic phenotype of human Marfan embryonic stem cells faithfully phenocopied by patient-specific induced-pluripotent stem cells. Proc. Natl. Acad. Sci. USA. 109:215-220. http://dx.doi.org/10.1073/ pnas. 1113442109

Ramirez, F., and L.Y. Sakai. 2010. Biogenesis and function of fibrillin assemblies. Cell Tissue Res. 339:71-82. http://dx.doi.org/10.1007/s00441009-0822-x

Ren, G., L. Zhang, X. Zhao, G. Xu, Y. Zhang, A.I. Roberts, R.C. Zhao, and Y. Shi. 2008. Mesenchymal stem cell-mediated immunosuppression occurs via concerted action of chemokines and nitric oxide. Cell Stem Cell. 2:141-150. http://dx.doi.org/10.1016/ j.stem.2007.11.014

Saidenberg-Kermanac'h, N., N. Bessis, D. Lemeiter, M.C. de Vernejoul, M.C. Boissier, and M. Cohen-Solal. 2004. Interleukin-4 cellular gene therapy and osteoprotegerin decrease inflammation-associated bone resorption in collagen-induced arthritis. J. Clin. Immunol. 24:370-378. http://dx.doi.org/10.1023/B:JOCI.0000029116.12371.bf

Sakai, L.Y., D.R. Keene, and E. Engvall. 1986. Fibrillin, a new 350-kD glycoprotein, is a component of extracellular microfibrils. J. Cell Biol. 103:2499-2509. http://dx.doi.org/10.1083/jcb.103.6.2499

Sallusto, F., C.R. Mackay, and A. Lanzavecchia. 1997. Selective expression of the eotaxin receptor CCR 3 by human T helper 2 cells. Science. 277:2005-2007. http://dx.doi.org/10.1126/science.277.5334.2005

Shaw, R.J., N. Bardeesy, B.D. Manning, L. Lopez, M. Kosmatka, R.A. DePinho, and L.C. Cantley. 2004. The LKB1 tumor suppressor negatively regulates mTOR signaling. Cancer Cell. 6:91-99. http://dx.doi .org/10.1016/j.ccr.2004.06.007

Shi, S., and S. Gronthos. 2003. Perivascular niche of postnatal mesenchymal stem cells in human bone marrow and dental pulp. J. Bone Miner. Res. 18:696-704. http://dx.doi.org/10.1359/jbmr.2003.18.4.696

Shi, S., S. Gronthos, S. Chen, A. Reddi, C.M. Counter, P.G. Robey, and C.Y. Wang. 2002. Bone formation by human postnatal bone marrow stromal stem cells is enhanced by telomerase expression. Nat. Biotechnol. 20:587-591. http://dx.doi.org/10.1038/nbt0602-587

Shoba, L.N., and J.C. Lee. 2003. Inhibition of phosphatidylinositol 3-kinase and p70S6 kinase blocks osteogenic protein-1 induction of alkaline phosphatase activity in fetal rat calvaria cells. J. Cell. Biochem. 88:1247-1255. http://dx.doi.org/10.1002/jcb.10474

Soleimani, M., and S. Nadri. 2009. A protocol for isolation and culture of mesenchymal stem cells from mouse bone marrow. Nat. Protoc. 4:102106. http://dx.doi.org/10.1038/nprot.2008.221

Song, L., M. Liu, N. Ono, F.R. Bringhurst, H.M. Kronenberg, and J. Guo. 2012. Loss of wnt/ $\beta$-catenin signaling causes cell fate shift of preosteoblasts from osteoblasts to adipocytes. J. Bone Miner. Res. 27:2344-2358. http://dx.doi.org/10.1002/jbmr.1694
Su, T.I., D. Khanna, D.E. Furst, G. Danovitch, C. Burger, P. Maranian, and P.J. Clements. 2009. Rapamycin versus methotrexate in early diffuse systemic sclerosis: results from a randomized, single-blind pilot study. Arthritis Rheum. 60:3821-3830. http://dx.doi.org/10.1002/ art. 24986

Sun, L., K. Akiyama, H. Zhang, T. Yamaza, Y. Hou, S. Zhao, T. Xu, A. Le, and S. Shi. 2009. Mesenchymal stem cell transplantation reverses multiorgan dysfunction in systemic lupus erythematosus mice and humans. Stem Cells. 27:1421-1432. http://dx.doi.org/10.1002/ stem. 68

Takai, S., H. Tokuda, Y. Hanai, A. Harada, E. Yasuda, R. MatsushimaNishiwaki, H. Kato, S. Ogura, T. Ohta, and O. Kozawa. 2007. Negative regulation by p70 S6 kinase of FGF-2-stimulated VEGF release through stress-activated protein kinase/c-Jun N-terminal kinase in osteoblasts. J. Bone Miner. Res. 22:337-346. http://dx.doi.org/10 $.1359 / \mathrm{jbmr} .061209$

Takai, S., Y. Hanai, R. Matsushima-Nishiwaki, C. Minamitani, T. Otsuka, H. Tokuda, and O. Kozawa. 2008. P70 S6 kinase negatively regulates fibroblast growth factor 2-stimulated interleukin-6 synthesis in osteoblasts: function at a point downstream from protein kinase C. $J$. Endocrinol. 197:131-137. http://dx.doi.org/10.1677/JOE-07-0560

Uccelli, A., and G. Mancardi. 2010. Stem cell transplantation in multiple sclerosis. Curr. Opin. Neurol. 23:218-225. http://dx.doi.org/10.1097/ WCO.0b013e328338b7ed

Uccelli, A., V. Pistoia, and L. Moretta. 2007. Mesenchymal stem cells: a new strategy for immunosuppression? Trends Immunol. 28:219-226. http:// dx.doi.org/10.1016/j.it.2007.03.001

Varga, J., and D. Abraham. 2007. Systemic sclerosis: a prototypic multisystem fibrotic disorder. J. Clin. Invest. 117:557-567. http://dx.doi.org/10.1172/ JCI31139

Wang, L., C.D. Fraley, J. Faridi, A. Kornberg, and R.A. Roth. 2003. Inorganic polyphosphate stimulates mammalian TOR, a kinase involved in the proliferation of mammary cancer cells. Proc. Natl. Acad. Sci. USA. 100:11249-11254. http://dx.doi.org/10.1073/pnas.1534805100

Wei, S., M.W. Wang, S.L. Teitelbaum, and F.P. Ross. 2002. Interleukin-4 reversibly inhibits osteoclastogenesis via inhibition of NF- $\mathrm{kB}$ and mitogen-activated protein kinase signaling. J. Biol. Chem. 277:6622-6630. http://dx.doi.org/10.1074/jbc.M104957200

Weinstein, R.S. 2010. Glucocorticoids, osteocytes, and skeletal fragility: the role of bone vascularity. Bone. 46:564-570. http://dx.doi.org/10 .1016/j.bone.2009.06.030

Woods, J.M., K.J. Katschke, M.V. Volin, J.H. Ruth, D.C. Woodruff, M.A. Amin, M.A. Connors, H. Kurata, K. Arai, G.K. Haines, et al. 2001. IL-4 adenoviral gene therapy reduces inflammation, proinflammatory cytokines, vascularization, and bony destruction in rat adjuvant-induced arthritis. J. Immunol. 166:1214-1222. http://dx.doi.org/10.4049/jimmunol .166 .2 .1214

Wynn, T.A. 2004. Fibrotic disease and the $\mathrm{T}(\mathrm{H}) 1 / \mathrm{T}(\mathrm{H}) 2$ paradigm. Nat. Rev. Immunol. 4:583-594. http://dx.doi.org/10.1038/nri1412

Xian, L., X. Wu, L. Pang, M. Lou, C.J. Rosen, T. Qiu, J. Crane, F. Frassica, L. Zhang, J.P. Rodriguez, et al. 2012. Matrix IGF-1 maintains bone mass by activation of mTOR in mesenchymal stem cells. Nat. Med. 18:1095-1101. http://dx.doi.org/10.1038/nm.2793

Yoon, K.H. 2009. Proliferation signal inhibitors for the treatment of refractory autoimmune rheumatic diseases: a new therapeutic option. Ann. N. Y. Acad. Sci. 1173:752-756. http://dx.doi.org/10.1111/j.1749-6632 .2009.04663.x

Yoshizaki, A., K. Yanaba, A. Yoshizaki, Y. Iwata, K. Komura, F. Ogawa, M. Takenaka, K. Shimizu, Y. Asano, M. Hasegawa, et al. 2010. Treatment with rapamycin prevents fibrosis in tight-skin and bleomycin-induced mouse models of systemic sclerosis. Arthritis Rheum. 62:2476-2487. http://dx.doi.org/10.1002/art.27498

Yu, W., Z. Chen, J. Zhang, L. Zhang, H. Ke, L. Huang,Y. Peng, X. Zhang, S. Li, B.T. Lahn, and A.P. Xiang. 2008. Critical role of phosphoinositide 3-kinase cascade in adipogenesis of human mesenchymal stem cells. Mol. Cell. Biochem. 310:11-18. http://dx.doi.org/10.1007/s11010-007-9661-9

Zhang, H., W. Hu, and F. Ramirez. 1995. Developmental expression of fibrillin genes suggests heterogeneity of extracellular microfibrils. J. Cell Biol. 129:1165-1176. http://dx.doi.org/10.1083/jcb.129.4.1165 
Zhang, H.H., J. Huang, K. Düvel, B. Boback, S. Wu, R.M. Squillace, C.L. $\mathrm{Wu}$, and B.D. Manning. 2009. Insulin stimulates adipogenesis through the Akt-TSC2-mTORC1 pathway. PLoS ONE. 4:e6189. http://dx.doi .org/10.1371/journal.pone.0006189

Zhang, J.F., W.M. Fu, M.L. He, H. Wang, W.M. Wang, S.C.Yu, X.W. Bian, J. Zhou, M.C. Lin, G. Lu, et al. 2011. MiR-637 maintains the balance between adipocytes and osteoblasts by directly targeting Osterix. Mol. Biol. Cell. 22:3955-3961. http://dx.doi.org/10.1091/mbc.E11-04-0356 Zhu, H., Z.K. Guo, X.X. Jiang, H. Li, X.Y. Wang, H.Y. Yao, Y. Zhang, and N. Mao. 2010. A protocol for isolation and culture of mesenchymal stem cells from mouse compact bone. Nat. Protoc. 5:550-560. http://dx .doi.org/10.1038/nprot.2009.238 